NBER WORKING PAPER SERIES

\title{
LOVE AND MONEY: A THEORETICAL AND EMPIRICAL ANALYSIS OF HOUSEHOLD SORTING AND INEQUALITY
}

\author{
Raquel Fernández \\ Nezih Guner \\ John Knowles \\ Working Paper 8580 \\ http://www.nber.org/papers/w8580 \\ NATIONAL BUREAU OF ECONOMIC RESEARCH \\ 1050 Massachusetts Avenue \\ Cambridge, MA 02138 \\ November 2001
}

We thank Michael Kremer and Torsten Persson for stimulating discussions of our paper in the NBER Economic Fluctuations and Growth Research Meeting and in the CEPR Public Policy Conference, respectively. We also wish to thank Daron Acemoglu, Orazio Attanasio, Oriana Bandiera, Jere Behrman, Jess Benhabib, Alberto Bisin, Jason Cummins, Paolo Dudine, Bill Easterly, Luca Flabbi, Chris Flinn, Mark Gertler, Sydney Ludvigson, Jonathan Portes, David Weil and participants in numerous seminars for helpful comments. We thank Miguel Szekely and Alejandro Gaviria at the IDB for assistance with the LatinAmerican data and the LIS and the statistical agencies of the Latin American countries in our sample for access to the surveys. The first and third authors acknowledge financial support from their respective NSF grants and the first author from the CV Starr Center as well. The views expressed herein are those of the authors and not necessarily those of the National Bureau of Economic Research.

(C) 2001 by Raquel Fernández, Nezih Guner and John Knowles. All rights reserved. Short sections of text, not to exceed two paragraphs, may be quoted without explicit permission provided that full credit, including (C) notice, is given to the source. 
Love and Money: A Theoretical and Empirical Analysis of

Household Sorting and Inequality

Raquel Fernández, Nezih Guner and John Knowles

NBER Working Paper No. 8580

November 2001

JEL No. D31, I21, J12, J31

\begin{abstract}
This paper examines the interactions between household matching, inequality, and per capita income. We develop a model in which agents decide whether to become skilled or unskilled, form households, consume and have children. We show that the equilibrium sorting of spouses by skill type (their correlation in education) is increasing as a function of the skill premium. In the absence of perfect capital markets, the economy can converge to different steady states, depending upon initial conditions. The degree of marital sorting, wage inequality, and fertility differentials are positively correlated across steady states and negatively correlated with per capita income. We use household surveys from 34 countries to construct several measures of the skill premium and of the degree of correlation of spouses' education (marital sorting). For all our measures, we find a positive and significant relationship between the two variables.
\end{abstract}

\author{
Raquel Fernández \\ Department of Economics \\ New York University \\ 269 Mercer Street \\ New York, NY 10003 \\ and NBER
}

\author{
Nezih Guner \\ Department of Economics \\ Pennsylvania State University \\ 619 Kern Graduate Building \\ University Park, PA 16802
}

John Knowles Department of Economics University of Pennsylvania 160 McNeil Building 3718 Locust Walk Philadelphia, PA 19104-6297 


\section{Introduction}

With a few notable exceptions, the analysis of household formation has played a relatively minor role in our understanding of macroeconomics. The vast majority of macroeconomic models tend to assume the existence of infinitely lived agents (with no offspring) or a dynastic formulation of a parent with children. ${ }^{1}$ While this may be a useful simplification for understanding a large range of phenomena, it can also lead to the neglect of potentially important interactions between the family and the macroeconomy. This is especially likely to be the case in those areas in which intergenerational transmission plays a critical role, such as human capital accumulation, income distribution, and growth.

The objective of this paper is to examine some of the interactions between household matching ("marriage"), inequality (as measured by the skill premium), fertility differentials and per capita output. The main idea that we wish to explore, theoretically and empirically, is the potentially reinforcing relationship between the strength of assortative matching by skill level and the degree of inequality. In particular, we wish to examine the notion that a greater skill premium may tend to make matches between different classes (skilled and unskilled workers in our model) of individuals less likely, as the cost of "marrying down" increases. In an economy in which borrowing constraints can limit the ability of individuals to acquire optimal levels of education, this private decision of whom to marry may have important social consequences. In particular, it can lead to inefficiently low aggregate levels of human capital accumulation and thus higher wage inequality between skilled and unskilled workers, larger fertility differentials across types of households, and lower per capita income. Thus, inequality and marital sorting are two endogenously determined variables that reinforce one another.

To explore the ideas sketched above, we develop a model in which individuals are either skilled or unskilled (according to education decisions made when young) and have a given number of opportunities in which to form a household with another agent. Once agents form households, they decide how much to consume and how many children to have. These children in turn decide whether to become skilled or unskilled workers. A decision to become skilled (synonymous here for acquiring a given level of education) is costly. To finance education, young individuals borrow in an imperfect capital market in which parental income plays the role of collateral. Thus parental income and the net return to being a skilled

\footnotetext{
${ }^{1}$ Even Becker and Tomes' $(1979,1986)$ pioneering work on intergenerational transmission of inequality assumes a one-parent household.
} 
versus unskilled worker, including the expected utility from one's future match, determine the proportion of children that in aggregate become skilled. These individuals then also meet and form households, have children, and so on.

We show that the steady state to which this economy converges will in general depend upon initial conditions. In particular, it is possible to have steady states with a high degree of sorting (skilled agents form households predominantly with others who are skilled; unskilled form households predominantly with unskilled), high inequality, and large fertility differentials. Alternatively, there can be steady states with a low degree of sorting, low inequality and low fertility differentials.

Our empirical analysis examines the main implication of our model: a positive correlation between the skill premium and marital sorting. To do this, we assemble a total of 34 country household surveys from the Luxembourg Income Study (LIS) and the Inter-American Development Bank (IDB) and use them to construct a sample of households for each country. From these samples we construct several measures of the skill premium as well as a measure of marital sorting-the correlation of spouses' years of education. In every country that we examine, we find a positive correlation between the education levels of spouses. For all our measures of the skill premium, we find a positive and significant relationship with marital sorting, even after controlling for other possible sources for this correlation. As implied by our model, we also find that marital sorting and per capita income are negatively correlated across countries.

Our work is related to several literatures. There is a rapidly growing literature on the intergenerational transmission of inequality in models with borrowing constraints. These models, though, either assume a dynastic formulation (e.g., Becker and Tomes (1986), Loury (1981), Ljungqvist (1993), Galor and Zeira (1993), Fernández and Rogerson (1998), Benabou (1996), Dahan and Tsiddon (1998), Durlauf (1995), Owen and Weil (1998), Knowles(1999) and Kremer and Chen (1999)) or consider a two-parent household in which the degree of sorting is exogenously specified (e.g. Kremer (1997) and Fernández and Rogerson (2001)). The last two papers are particularly relevant as they are concerned with whether an (exogenous) increase in marital sorting can lead to a quantitatively significant increase in inequality. In our model, on the other hand, sorting and inequality are endogenously determined. There is also a theoretical literature that focuses on the determinants of who matches with whom, but that basically abstracts from the endogeneity of the income distribution in the economy (the seminal paper in this literature is Becker (1973). See also, for example, Cole, Mailath, and 
Postlewaite (1992), and Burdett and Coles $(1997,1999)) .{ }^{2}$ Our paper, therefore, is related to the two literatures, and can be seen as trying to integrate both concerns into a simple, analytical framework. Some recent work that also shares our concerns, but that is more focused on fertility, marriage and divorce, are Aiyagari, Greenwood, Guner (2000), Greenwood, Guner, and Knowles (2000), and Regalia and Rios-Rull (1999). The models, not surprisingly, are more complicated and rely on computation to obtain solutions for particular parameter values.

There is also a small, mostly descriptive, empirical literature that is related to our work. As reviewed by Lam (1988), the general finding in the literature is the existence of positive assortative matching across spouses. Mare (1991) documents the correlation between spouses' schooling in the US since 1930s. Using a large cross section of countries, Smith, Ultee, and Lammers (1998) find that the relation between marital sorting and some indicators for development (such as per capita energy consumption and the proportion of the labor force not in agriculture) has an inverted-U shape. Dahan and Gaviria (1999) report a positive relation between inequality and marital sorting for Latin American countries. Boulier and Rosenzweig (1984) document assortative matching with respect to schooling and sensitivity to marriage market variables using data from the Philippines.

\section{The Model}

In this section we present a model of matching, fertility and inequality. Each component of the model is kept relatively simple in the interest of highlighting the interactions among all three variables, both at a given moment in time and over the longer run.

\subsection{Timing}

The economy is populated by overlapping generations that live for three periods. At the beginning of the first period, young agents make their education decisions by deciding whether to become skilled or unskilled. This decision made, they then meet in what we call a "household matching market". Here they find another agent with whom to form a household, observing both the agent's skill

\footnotetext{
${ }^{2}$ Laitner (1979), on the other hand, endogenzes bequests (but not labor earnings) and hence the income distribution. He assumes, however, that matches are randomly determined. See Bergstrom (1997) and Weiss (1997) for a survey of the literature on theories of the family and household formation.
} 
type (and hence able to infer that agent's future income) and a match specific quality. In the second period, the now adult agents work in the labor market, pay their education debt (if any) and have children. In the last period, households consume their income net of debt repayment (and of the resources absorbed by children).

We now describe in more detail each aspect of an agent's decision problem. We begin with the decision problem at the beginning of the second period, when agents have already formed a household of some given quality.

\subsection{The Household's Problem}

In this model we abstract from bargaining problems among agents within a household and instead assume that spouses share a common joint utility function. ${ }^{3}$ We also abstract away from any differences between women and men, either exogenous (e.g., childbearing costs) or cultural/institutional (e.g., the degree of wage discrimination or the expected role of woman in the home relative to the workplace) ${ }^{4}{ }^{-}$

Having matched in the first period of life and attained a match quality $q$, at the beginning of period 2 each household decides how many children, $n$, to have (and hence how much to consume, $c$, in period 3). Raising children is costly; each child consumes a fraction $t$ of parental income, $I .^{5}$

The utility of a household with match quality $q$ and income $I$ is given by solving:

$$
\max _{c, n \geq 0}[c+\beta \log n+\gamma+q]
$$

subject to

$$
c \leq I(1-t n)
$$

\footnotetext{
${ }^{3}$ For models that focus on intrafamily bargaining problems, see, for example, Bergstrom (1997) and Weiss (1997).

${ }^{4}$ This assumption considerably simplifies our analysis. See the conclusion for a brief discussion of alternative modelling assumptions.

${ }^{5}$ Traditionally the cost of having children is thought of as the opportunity cost of time. While in our model this interpretation is possible at the level of the individual budget constraint, we choose not to view it this way since, at the aggegate production function level, it is simpler if we do not have to take into account how hours of work vary across individuals (on account of different incomes implying different numbers of children). Instead we model the cost of children directly as a proportional consumption cost (perhaps as a result of bargaining in the household). An alternative route would have been to model a quality-quantity tradeoff in the production of children. We also allow the number of children to be a continuous rather than discrete variable to simplify the analysis.
} 
where $\beta, t>0$, and $\gamma$ is a constant. Note that the way we have modelled match quality renders the solution to the optimization problem independent of $q$.

The household utility function implies that for household income below $\beta$, households will dedicate all their income to children and have $\bar{n}=\frac{1}{t}$ of them, yielding utility $\beta \log \bar{n}+\gamma+q$. An interior solution to (2.1) is given by:

$$
n=\frac{\beta}{t I}
$$

and

$$
c=I-\beta
$$

Without loss of generality, by setting $\gamma=\beta \log t+\beta-\beta \log \beta$ we can write the indirect utility function for a couple with match quality $q$ and household income $I>\beta$ as:

$$
V(I, q)=I-\beta \log I+q, \text { for } I>\beta
$$

Note the comparative statics of the solution to the household's optimization problem. For values of household income below $\beta$, couples have a constant number of children and their utility is unaffected by increases in income within this range. For household income above $\beta$, increases in income increase consumption and reduce the number of children in the household. Thus, for $I>\beta$, wealthier households have fewer children and the fertility differential across income groups is increasing with income inequality. ${ }^{6}$

We next turn to the determination of household income.

\subsection{The Labor Market}

Agents are employed as workers in the second period of their lives. Workers are either skilled $(s)$ or unskilled $(u)$. We assume that technology is constant returns to scale and that wages are the outcome of a competitive labor market in which

\footnotetext{
${ }^{6}$ Fertility declining with income is consistent both with the cross-country evidence on fertility and per capita income (e.g., Perotti (1996)) and with cross-sectional evidence from US data (see Knowles (1999) and Fernández and Rogerson (2001)). Furthermore, Kremer and Chen (1999) find that the fertility differential between low and high income families is increasing in the degree of inequality which is also implied by our model.
} 
skilled and unskilled workers are employed to produce an aggregate consumption good.

Given a composition of the labor force $L$ into skilled or unskilled workers $(L=$ $L_{s}+L_{u}$ ), and denoting by $\lambda$ the proportion of skilled workers in the population, full employment and constant returns to scale imply that output is given by:

$$
F\left(L_{s}, L_{u}\right) \equiv L F(\lambda, 1-\lambda) \equiv L_{u} F\left(\frac{\lambda}{1-\lambda}, 1\right) \equiv L_{u} f(k)
$$

where $k \equiv \frac{\lambda}{1-\lambda}$. Hence wages depend only on $\lambda$ :

$$
w_{s}=f^{\prime}(k) \text { and } w_{u}=f-f^{\prime} k
$$

We will often find it more convenient to work with the net return to being skilled which we denote by $\widetilde{w}_{s} \equiv w_{s}-d$, where $d$ is the (constant) monetary cost of becoming skilled. Note that $\widetilde{w}_{s}$ is decreasing in $\lambda, w_{u}$ is increasing in $\lambda$, and thus that the skill premium is a decreasing function of the fraction of skilled workers.

Household income $I_{i j}$ is simply the sum of each partner's ( $i$ and $j$ ) wages. To simplify our analysis, we will assume that household income is always greater than $\beta$ as this ensures an interior solution to the household maximization problem (as discussed in the previous section). We can do this either by imposing conditions on the production function such that the unskilled wage has a given positive lower bound of $\frac{\beta}{2}$ or by assuming that individuals are endowed with $e>\frac{\beta}{2}$ units of income. Thus, we assume:

$$
2 w_{u}>\beta
$$

where $w_{u}$ can be interpreted as the market wage (as in the first explanation) or as the market wage plus the endowment (as in the second explanation).

\subsection{Household Matching}

The choice of whom to match with is of course driven by many factors: tastes, one's environment (e.g., who one gets to know and the distribution of characteristics of individuals), and the prospects for one's material and emotional wellbeing. We provide a simple model in which we allow all these factors to interact to produce a household match. 
Households can be categorized by the skill types of its two partners. Let $I_{i j}$ denote the household income for a couple composed by skill types $i, j \in\{s, u\}$. Thus,

$$
I_{i j}= \begin{cases}2 \widetilde{w}_{s}, & \text { if } i j=s s \\ \widetilde{w}_{s}+w_{u}, & \text { if } i j=s u \\ 2 w_{u}, & \text { if } i j=u u\end{cases}
$$

We assume that in the first period, once their education decisions have been made, agents have two opportunities to match and form a household. In the first round, all agents meet randomly and draw a random match-specific quality $q$. This match can be accepted by both agents resulting in a "marriage" or rejected by at least one of the agents whereupon both agents enter the second round of matching. In the second round, agents are matched non-randomly with their own skill group and draw a new random match quality. We assume that qualities are match-specific i.i.d draws from the same cumulative distribution function $Q$ (with its pdf denoted by $Q^{\prime}$ ), and with expected value $\mu$ and support $[0, \bar{q}]^{7}$

The two rounds of matching - one at random and the second exclusively with one's own skill type - are meant to reflect the fact that as time progresses people tend to be more likely to interact more with others who are similar in skill/education level (e.g., individuals who go on to college meet other people also in college, whereas individuals who work in low-skill jobs tend to have more contact with other individuals of the same skill level). ${ }^{8}$ Note that a skilled agent (with a high wage) that encounters an unskilled agent (with a low wage) in the first round and draws a high $q$ will face a tradeoff between forming a lower-income household with a high quality match and a higher-income household (by matching for sure with a skilled agent in the second round) but of an unknown quality (i.e., there is a tradeoff of "love versus money").

\footnotetext{
${ }^{7}$ The assumption of $q \geq 0$ ensures that all agents will form a household in the second round. Although unrealistic, this allows us to abstract from the issue of how inequality affects the decision to remain single, which is not the focus of the analysis here. In our comparative static analysis, we will assume that $\bar{q}$ is sufficiently large so that in equilibrium some matches occur between skilled and unskilled individuals. This is for simplicity only.

${ }^{8}$ Alternative modelling assumptions (e.g., more periods, search or waiting costs, and assuming individuals always meet others at random) are also possible and can give rise to similar properties as this one. This formulation is simple and avoids problems of multiple equilibria that can arise when the fraction of types an individual meets evolves endogenously over time. See Fernández and Pissarides (2001) for an infinite horizon search model for household partners.
} 
Let $V_{i j}(q)$ denote the utility of a couple with income $I_{i j}$ and match quality $q$ (as expressed in (2.4)) where $i, j \in\{s, u\}$. As a skilled agent's second-round option dominates that of an unskilled agent (given $\widetilde{w}_{s} \geq w_{u}$, which is a necessary condition in order for any individual to choose to become a skilled worker), it is the skilled agent who determines whether a match between a skilled and an unskilled agent is accepted.

A skilled agent is indifferent between accepting a first-round match with an unskilled agent and proceeding to the second round if $V_{s u}(q)=V_{s s}(\mu)$. Solving for the level of $q$ at which this occurs, $q^{*}$, yields a threshold quality of:

$$
q^{*}=I_{s s}-I_{s u}-\beta \log \left(\frac{I_{s s}}{I_{s u}}\right)+\mu
$$

which, after substituting for wages, yields:

$$
q^{*}(\lambda)=\widetilde{w}_{s}(\lambda)-w_{u}(\lambda)-\beta \log \left(\frac{2 \widetilde{w}_{s}(\lambda)}{\widetilde{w}_{s}(\lambda)+w_{u}(\lambda)}\right)+\mu
$$

The intuition underlying (2.8) is clear. A skilled individual who matches with an unskilled one in the first round knows that by foregoing that match she will meet a skilled individual in the second round with an expected match quality of $\mu$. Thus, the match quality of the unskilled individual must exceed $\mu$ by the amount required to compensate for the decreased utility arising from the fall in household income. Of course, the threshold quality for two agents of the same type to match in the first round is $\mu$ as this is the expected value of next round's match quality and there is no difference in household income.

Given a distribution of individuals into skilled and unskilled, we can find the fraction of households that will be composed of two skilled individuals, two unskilled individuals, and one skilled and one unskilled. The fraction of households of each type depends only on the probability of types meeting in the first round and on $q^{*}$. Both of these are only a function of $\lambda_{t}$ since this variable determines both household incomes and first round matching probabilities. Denoting by $\rho_{i j}$ the fraction of households formed between agents of skill type $i$ and $j, i, j \in\{s, u\}$ (with $\rho_{s u}=\rho_{u s}$ ), these are given by:

$$
\rho_{i j}\left(\lambda_{t}\right)= \begin{cases}\lambda_{t}^{2}+\lambda_{t}\left(1-\lambda_{t}\right) Q\left(q^{*}\left(\lambda_{t}\right)\right), & \text { if } i j=s s \\ 2 \lambda_{t}\left(1-\lambda_{t}\right)\left(1-Q\left(q^{*}\left(\lambda_{t}\right)\right),\right. & \text { if } i j=s u \\ \left(1-\lambda_{t}\right)^{2}+\lambda_{t}\left(1-\lambda_{t}\right) Q\left(q^{*}\left(\lambda_{t}\right)\right), & \text { if } i j=u u\end{cases}
$$


Note that $Q\left(q^{*}\right)$ is a measure of the degree of sorting that occurs. If individuals were not picky and simply matched with whomever they met in the first round, then $q^{*}$ would equal zero and $\rho_{s u}$ would equal the probability of a skilled and an unskilled individual meeting, i.e., $2 \lambda_{t}\left(1-\lambda_{t}\right)$. If individuals simply cared about quality and not about income, then $q^{*}$ would equal $\mu$. Lastly, if individuals cared only about income and not about match quality, then $Q\left(q^{*}\right)$ would equal one and there would be no matches between skilled and unskilled agents.

Remark 1. $Q\left(q^{*}\right)$ is the correlation coefficient between different skill types in households. ${ }^{9}$

The observation above will be very useful when we examine the data as although the fractions of couples of each type that form may have ambiguous comparative statics with respect to $\lambda$ (as we discuss below), this is not true for the degree of sorting (i.e., for the correlation coefficient). This is stated in the theorem and corollary below.

Theorem 2.1. An increase in the skill premium $\frac{w_{s}}{w_{u}}$, ceteris paribus, will increase the degree of sorting.

Proof: Recall that the degree of sorting is given by $Q\left(q^{*}\right)$. It follows immediately from (2.8) that

$$
\frac{\partial q^{*}}{\partial \widetilde{w}_{s}}>0, \quad \frac{\partial q^{*}}{\partial w_{u}}<0
$$

and hence $\frac{d Q\left(q^{*}\right)}{d \frac{w_{s}}{w_{u}}}>0 . \|$

The theorem above implies that an exogenous increase in inequality (say, from a skill-biased technology shock) will increase sorting by making skilled workers less willing to form households with unskilled workers.

Corollary 2.2. A decrease in $\lambda$ will increase the degree of sorting. ${ }^{10}$

\footnotetext{
${ }^{9}$ This is most easily seen by setting $Q$ equal to zero in 2.9 and noting that in that case the fractions of each marital type would be those predicted purely by random matching (and hence would have a zero correlation).

${ }^{10} \mathrm{~A}$ feature of our matching model is that $\lambda$ only affects the degree of sorting through its effect on the skill premium (since that is what determines $q^{*}$ ). A more general model of matching would have the proportion of individuals of different types in the matching market evolve endogenously as a result of matches made in previous rounds. This would then produce a dependence of the correlation on the initial fraction of skilled individuals, independently of the latter's effect on the skill premium. In our empirical work, we control for this possible independent channel.
} 
Proof: $\quad$ Note that $\frac{d \widetilde{w}_{s}}{d \lambda}=f^{\prime \prime} \frac{d k}{d \lambda}<0, \frac{d \widetilde{w}_{u}}{d \lambda}=-f^{\prime \prime} k \frac{d k}{d \lambda}>0$, where $\frac{d k}{d \lambda}=\frac{1}{(1-\lambda)^{2}}$. Hence, the conclusion follows immediately from the theorem above.||

The intuition for the corollary above is that a decrease in $\lambda$ increases the skill premium and thus makes skilled workers less willing to form matches with unskilled workers. One might ask, however, how does a change in proportion of skilled workers in the population affect the fraction of households of each type? An increase in the $\lambda$ will unambiguously decrease the fraction of couples that are $u u$ as, for any given $q^{*}$ they are less likely to end up in $u$ households. Furthermore, $q^{*}$ will decrease, thereby increasing the probability that a first round match between a high and low skilled worker will result in a household. The effect on us and ss households, on the other hand, is ambiguous (although the aggregate fraction of the population that is in one of these two types of households must of course increase). For any given $q^{*}$, the fraction of $s s$ households increases, but as a skilled individual is now more willing to match with an unskilled one, this will work to decrease the fraction of $s s$ households. The effect on us households is positive if $\lambda \leq 1 / 2$ (as both the likelihood of $s$ and $u$ individuals meeting in the first round increases as does the probability that the match will be accepted) and ambiguous otherwise.

The main focus of our empirical work will be in establishing the positive correlation implied above between the skill premium and the degree of sorting in households across countries. Why should different countries have different de-

grees of inequality, however? This is the question that the model next turns to by examining the determinants of a young agent's decision to become a skilled relative to an unskilled worker.

\subsection{Education Decisions and Capital Markets}

A young agent's desire to become skilled depends on the return to being a skilled relative to an unskilled worker. Note that this depends not only on net wages next period, but also on the expected return to matching at the household level. The expected value of being a skilled worker given that a fraction $\lambda_{t+1}$ of the population also becomes skilled is given by:

$$
\begin{aligned}
V^{s}\left(\lambda_{t+1}\right)= & \lambda_{t+1} \int_{0}^{\bar{q}} \max \left[V_{s s}\left(x ; \lambda_{t+1}\right), V_{s s}\left(\mu ; \lambda_{t+1}\right)\right] d Q(x) \\
& +\left(1-\lambda_{t+1}\right) \int_{0}^{\bar{q}} \max \left[V_{s u}\left(x ; \lambda_{t+1}\right), V_{s s}\left(\mu ; \lambda_{t+1}\right)\right] d Q(x)
\end{aligned}
$$


whereas the expected value of being an unskilled worker is:

$$
\begin{aligned}
V^{u}\left(\lambda_{t+1}\right)= & \lambda_{t+1}\left[\int_{0}^{q *} V_{u u}\left(\mu ; \lambda_{t+1}\right) d Q(x)+\int_{q *}^{\bar{q}} V_{s u}\left(x ; \lambda_{t+1}\right) d Q(x)\right] \\
& +\left(1-\lambda_{t+1}\right) \int_{0}^{\bar{q}} \max \left[V_{u u}\left(x ; \lambda_{t+1}\right), V_{u u}\left(\mu ; \lambda_{t+1}\right)\right] d Q(x)
\end{aligned}
$$

We assume that in addition to a monetary cost of $d$, becoming a skilled worker entails an additive non-pecuniary cost of $\delta \in[0, \infty]$. This cost can be thought of as effort and it is assumed to be identically and independently distributed across all young agents with cumulative distribution function $\Phi$. Thus, an agent with idiosyncratic $\operatorname{cost} \delta_{i}$ will desire to become skilled if $V^{s}-V^{u} \geq \delta_{i}$.

We define by $\delta^{*}(\lambda)$ the skilled-unskilled payoff difference generated when a fraction $\lambda$ of the population is skilled, i.e.,

$$
\delta^{*}\left(\lambda_{t+1}\right) \equiv V^{s}\left(\lambda_{t+1}\right)-V^{u}\left(\lambda_{t+1}\right)
$$

Note that given $\delta^{*}$, all agents with $\delta_{i} \leq \delta^{*}$ would want to become skilled. If young agents were able to borrow freely, children from all household types would make identical education decisions contingent only on their value of $\delta_{i}$. Hence in equilibrium a fraction $\Phi\left(\delta^{*}\right)$ of each family would become skilled yielding $\lambda_{t+1}=$ $\Phi\left(\delta^{*}\right)$ and

$$
\delta^{*}\left(\Phi\left(\delta^{*}\right)\right) \equiv V^{s}\left(\Phi\left(\delta^{*}\right)\right)-V^{u}\left(\Phi\left(\delta^{*}\right)\right)
$$

If, however, parental income is a factor that influences a child's access to capital markets (either in terms of the interest rate faced or in determining whether they are rationed in the amount they are able to borrow), then children of different household types may make different education decisions although they have the same $\delta_{i}$. In this case, the fraction of children of different household types that become skilled will depend on the parental household income distribution, and thus on $\lambda_{t} \cdot{ }^{11}$

\footnotetext{
${ }^{11}$ It is important to note that this constraint should not be interpreted literally as the inability to borrow freely to attend college. It could also reflect parental inability to borrow against their children's future human capital so as to live in a neighborhood in which the quality of primary and secondary public education is high or to opt out of public education for a high-quality private education. It is the quality of this earlier education that then determines the probability of an individual attending college even if the latter is free.
} 
In particular, we assume that children within a family with household income $I$ can borrow on aggregate up to $Z(I), Z^{\prime}>0$. One way to think about this constraint is that parents can act as monitoring devices for their children in an incentive compatible fashion by putting their own income up for collateral (in period 2 of their lives). This ensures that the children will use the funds to become educated rather than for consumption and allows up to $Z(I)$ to be borrowed by the family's children. Hence, a family with income $I$ and $n(I)$ children can at most afford to educate at a cost $d$ per child a fraction $\Phi(\widehat{\delta}(I))$ implicitly defined by: ${ }^{12}$

$$
\frac{Z(I)}{n(I) \Phi(\widehat{\delta})}=d
$$

Note that as indicated in (2.15), children from families with low household income are hampered in their ability to become skilled both because of the lower aggregate amount that can be borrowed by the family and because of the larger number of children (recall that $n$ is decreasing in $I$ ) that want to become skilled and hence must share these funds.

Thus, given $\lambda_{t}$ (and hence family income and number of children by family type), in equilibrium a fraction

$$
\pi_{i j}\left(\lambda_{t}, \lambda_{t+1}\right) \equiv \min \left[\Phi\left(\delta^{*}\left(\lambda_{t+1}\right)\right), \Phi\left(\widehat{\delta}\left(I_{i j}\left(\lambda_{t}\right)\right)\right)\right]
$$

of each family type will become skilled. ${ }^{13}$

\subsection{Equilibrium}

Given a division of the young population into skilled and unskilled in period $t$, i.e., $\lambda_{t}$, an equilibrium for that period is a skilled and unskilled wage pair $\left(w_{s}\left(\lambda_{t}\right), w_{u}\left(\lambda_{t}\right)\right)$ given by (2.5), a threshold match quality (between skilled and unskilled agents) of $q^{*}\left(\lambda_{t}\right)$ given by (2.8), which generates a division of families into types $\rho_{i j}\left(\lambda_{t}\right)$ as given by (2.9). It also includes a decision by the children of these individuals to become skilled or unskilled next period such that given that the expected value of $\lambda$ in the next period is $\lambda_{t+1}$ and hence the differential

\footnotetext{
${ }^{12}$ We are implicitly normalizing the gross interest rate to equal one. Note that as we are not endogenizing the supply of funds for loans, it is best to think of loans being provided on a world market (in which this country is small).

${ }^{13} \mathrm{We}$ are assuming that the decision regarding which children should obtain the funding to become skilled is efficient, i.e., those who have the lowest $\delta$ are the first to become skilled.
} 
between the expected value of being a skilled or unskilled worker is $\delta^{*}\left(\lambda_{t+1}\right)$, a fraction $\pi_{i j}\left(\lambda_{t}, \lambda_{t+1}\right)$ given by (2.16) of each family type becomes skilled, and in aggregate these constitute a proportion $\lambda_{t+1}$ of next period's population.

Figure 1 depicts the equilibrium $\lambda_{t+1}$ generated by a given $\lambda_{t}$. The upward sloping line, $\delta=\Psi\left(\lambda_{t+1} ; \lambda_{t}\right)$, is derived in the following fashion. For a given $\lambda_{t}$, it shows what $\delta$ would have to be such that the fraction of young individuals with $\delta_{i} \leq \delta$ that would be able to afford to enter the following period as skilled equals $\lambda_{t+1}$. Note that the domain of this function can in general be smaller than 1 since for some initial conditions not all individuals will be able to afford to become skilled even if $\delta \rightarrow \infty$. In the absence of borrowing constraints, the inverse of this function would coincide with $\Phi(\delta)$ and the unconstrained $\Psi(\cdot)$ curve is the lower envelope of the family of curves parameterized by different values of $\lambda_{t}$. The downward sloping curve shows $\delta^{*}\left(\lambda_{t+1}\right) \equiv V^{s}\left(\lambda_{t+1}\right)-V^{u}\left(\lambda_{t+1}\right)$ as a function of $\lambda_{t+1}$. Note that this curve does not depend on $\lambda_{t}$. The intersection of these two curves gives the equilibrium values of $\left(\delta^{* *}, \lambda_{t+1}^{* *}\right)$ given $\lambda_{t}$.

Existence of an interior equilibrium (for any initial $\lambda_{t}$ ) is guaranteed if we assume that $\widetilde{w}_{s}(\lambda)<w_{u}(\lambda)$ for some $\lambda \in(0,1)$ (i.e., such that no one finds it in their interest to become skilled) and that for some other $\lambda \in(0,1)$ the inequality is reversed. ${ }^{14}$ Note that the $\Psi$ curve is continuous, upward sloping, starts at zero, and becomes vertical once all family groups are constrained. Thus, this and the fact the $\delta^{*}\left(\lambda_{t+1}\right)$ is a continuous function defined over the entire range of $[0,1]$ and goes from strictly positive to strictly negative numbers, guarantees the existence of an interior equilibrium. Uniqueness of equilibrium (for any given $\lambda_{t}$ ) is guaranteed if $\delta^{*}$ is monotonically decreasing in $\lambda$. This may, however, not be the case as discussed in the next section.

\subsection{Inequality}

In order to investigate the effects of inequality on household sorting and education decisions, we first examine how exogenous changes in inequality affect education choices in any given period (i.e., we examine the effect of changes in wages taking $\lambda$ as given).

An increase in $\widetilde{w}_{s}$ makes becoming a skilled worker more attractive as it increases the direct return to being skilled. It also increases the return to matching with another skilled worker, making skilled agents pickier in their household matching, i.e., it increases $q^{*}$. On the other hand, an increase in $\widetilde{w}_{s}$ has ambiguous

\footnotetext{
${ }^{14}$ This is guaranteed, for example, by assuming Inada conditions on the production function.
} 
effects on an unskilled agent's payoff since although it increases the value of being in a household with a skilled worker, it also makes these matches more unlikely. It is easy to show that an increase in $\widetilde{w}_{s}$ increases the relative desirability of being a skilled relative to an unskilled worker, i.e.,

$$
\begin{aligned}
\frac{d \delta^{*}}{d \widetilde{w}_{s}}= & \frac{d\left[V^{s}-V^{u}\right]}{d \widetilde{w}_{s}} \\
= & {\left[\lambda+(1-\lambda) Q\left(q^{*}\right)\right] \frac{\partial V_{s s}}{\partial \widetilde{w}_{s}}+\left[\left(1-Q\left(q^{*}\right)\right)(1-2 \lambda)\right] \frac{\partial V_{s u}}{\partial \widetilde{w}_{s}} } \\
& -\frac{d q^{*}}{d \widetilde{w}_{s}} \lambda\left[V_{u u}(\mu)-V_{s u}\left(q^{*}\right)\right] Q^{\prime}\left(q^{*}\right)
\end{aligned}
$$

which is strictly positive as $\frac{\partial V_{s s}}{\partial w_{s}}=2-\frac{\beta}{w_{s}}>\frac{\partial V_{s u}}{\partial w_{s}}=1-\frac{\beta}{w_{s}+w_{u}}, \lambda+(1-\lambda) Q\left(q^{*}\right)>$ $\left(1-Q\left(q^{*}\right)\right)(1-2 \lambda), \frac{d q^{*}}{d w_{s}}>0$ and $V_{u u}(\mu)-V_{s u}\left(q^{*}\right)<0$ (with the latter following from the fact that skilled workers choose a higher cutoff quality level in their matches with unskilled individuals than what the latter find optimal). ${ }^{15}$

An increase in $w_{u}$, on the other hand, has ambiguous effects on the relative desirability of being a skilled worker relative to an unskilled worker, as

$$
\begin{aligned}
\frac{d \delta^{*}}{d w_{u}}= & {\left[\left(1-Q\left(q^{*}\right)\right)(1-2 \lambda)\right] \frac{\partial V_{s u}}{\partial w_{u}}-\left[1-\lambda+\lambda Q\left(q^{*}\right)\right] \frac{\partial V_{u u}}{\partial w_{u}} } \\
& +\frac{d q^{*}}{d w_{u}} \lambda\left[V_{s u}\left(q^{*}\right)-V_{u u}(\mu)\right] Q^{\prime}\left(q^{*}\right),
\end{aligned}
$$

The expression on the second line is negative but the expression on the first line, which can be written as $-1-Q\left(q^{*}\right)+\frac{\beta}{w_{u}\left(w_{u}+w_{s}\right)}\left[w_{s}\left(\lambda Q\left(q^{*}\right)+1-\lambda\right)+w_{u}\left(Q\left(q^{*}\right)+\right.\right.$ $\left.\lambda\left(1-Q\left(q^{*}\right)\right)\right]$ is ambiguous. ${ }^{16}$

We next turn to an analysis of the effect of an increase in $\lambda$ on the relative attractiveness of becoming skilled. Note that a change in the fraction of the population that plans to become skilled will have two effects (i) it will change wages and hence household incomes by changing the ratio of skilled to unskilled workers in aggregate production; (ii) it will change the probability with which

\footnotetext{
${ }^{15}$ For notational convenience, we have supressed everywhere the dependence of $V_{i j}$ on $\lambda$.

${ }^{16}$ This ambiguity is due to the fact that an increase in $w_{u}$ also makes a skilled worker better off (as the return to matching with an unskilled individual increase) and, as our indirect utility function is convex in income, this effect could in theory outswamp the direct effect of the increase in $w_{u}$ on $V^{u}$.
} 
individuals encounter skilled relative to unskilled workers in the first round of matching, (i.e., $\lambda$ ). So, the total effect on the payoff differential $\delta^{*}$ between skilled and unskilled agents is given by:

$$
\frac{d \delta^{*}}{d \lambda}=\frac{\partial\left[V^{s}-V^{u}\right]}{\partial \widetilde{w}_{s}} \frac{d \widetilde{w}_{s}}{d \lambda}+\frac{\partial\left[V^{s}-V^{u}\right]}{\partial w_{u}} \frac{d w_{u}}{d \lambda}+\frac{\partial \delta^{*}(\lambda)}{\partial \lambda}
$$

Note that we can rewrite $\delta^{*}$ as:

$$
\begin{aligned}
\delta^{*}= & \lambda\left[V_{s s}(\mu) Q(\mu)+\int_{\mu}^{\bar{q}} V_{s s}(x) d Q(x)-\int_{q^{*}}^{\bar{q}} V_{s u}(x) d Q(x)-V_{u u}(\mu) Q\left(q^{*}\right)\right] \\
& +(1-\lambda)\left[V_{s s}(\mu) Q\left(q^{*}\right)+\int_{q^{*}}^{\bar{q}} V_{s u}(x) d Q(x)-V_{u u}(\mu) Q(\mu)-\int_{\mu}^{\bar{q}} V_{u u}(x) d Q(x)\right]
\end{aligned}
$$

which after substituting in (2.4) and (2.6) yields:

$$
\begin{aligned}
\delta^{*}= & \left(\widetilde{w}_{s}-w_{u}\right)\left(1+Q\left(q^{*}\right)\right)+(2 \lambda-1) \int_{\mu}^{q^{*}}(x-\mu) d Q(x) \\
& +(2 \lambda-1)\left(1-Q\left(q^{*}\right)\right) \beta \log \left(\widetilde{w}_{s}+w_{u}\right) \\
& -\left(\lambda+(1-\lambda) Q\left(q^{*}\right)\right) \beta \log 2 \widetilde{w}_{s}+\left(1-\lambda+\lambda Q\left(q^{*}\right)\right) \beta \log 2 w_{u} .
\end{aligned}
$$

Taking the derivative of $\delta^{*}$ with respect to $\lambda$ yields (after some manipulation):

$$
\begin{aligned}
\frac{d \delta^{*}}{d \lambda}= & R\left\{\left(1+2 k Q\left(q^{*}\right)+k^{2}\right)\left(\widetilde{w}_{s}+w_{u}-\beta\right)+\left(2 k+Q\left(q^{*}\right) k^{2}+Q\left(q^{*}\right)\right)\left(\widetilde{w}_{s}+w_{u}\right)\right. \\
& \left.-\left(k+Q\left(q^{*}\right)\right) \beta \frac{w_{u}}{\widetilde{w}_{s}}-\left(k+k^{2} Q\left(q^{*}\right)\right) \beta \frac{\widetilde{w}_{s}}{w_{u}}\right\}+ \\
& Q^{\prime}\left(q^{*}\right) \frac{\partial q^{*}}{\partial \lambda} \lambda\left[2\left(\widetilde{w}_{s}-w_{u}\right)-\beta \log \frac{\widetilde{w}_{s}}{w_{u}}\right]+\left\{2 \int_{\mu}^{q^{*}}(x-\mu) d Q(x)\right. \\
& \left.+\beta\left[2 \log \left(\widetilde{w}_{s}+w_{u}\right)-\log \left(2 \widetilde{w}_{s}\right)-\log \left(2 w_{u}\right)\right]\left[1-Q\left(q^{*}\right)\right]\right\} .
\end{aligned}
$$

where $R=\frac{f^{\prime \prime}}{\left(w_{s}+w_{u}\right)} \frac{1}{(1+k)} \frac{d k}{d \lambda}<0$.

In order to sign $\frac{d \delta^{*}}{d \lambda}$, note that all expressions other than the last one in curly brackets are negative. To see this, note that, as shown in Appendix A, the sign of the expression in the first curly parenthesis (the first two lines) of (2.18) is positive (which, as multiplied by $R<0$ implies that the first two lines are negative) and 
that $\frac{\partial q^{*}}{\partial \lambda}<0$ (and the expression multiplying it is positive). Unfortunately, we are not unambiguously able to sign the equation as the effect of a change in $\lambda$ on the matching component is strictly positive (i.e., $\frac{d \lambda}{d k}>0, \int_{\mu}^{q^{*}}(x-\mu) d Q(x)>0$, and the expression on the fourth line is positive since $\log x$ is a concave function).

The ambiguity in (2.18) above is due to the fact that although an increase in $\lambda$ decreases skilled wages and increases unskilled wages, thereby making it less attractive to become skilled than previously, it also increases the probability of matching with a skilled agent in the first round. As the indirect utility function is convex in income, then for a given cutoff level of $q^{*}$, the increased probability of meeting a skilled individual on the margin yields greater utility to another skilled individual.

Thus, we cannot rule out the existence of multiple equilibria, though simulation of the model for various functional forms and parameter values always resulted in a unique equilibrium. The rest of our discussion, in any case, will ignore this possibility and simply assume

$$
\frac{d \delta^{*}(\lambda)}{d \lambda}<0
$$

as this type of multiplicity is not the focus of our analysis.

\subsection{Steady States and Dynamics}

The state variable for this economy is the fraction of skilled workers, $\lambda$. The evolution of this variable is given by:

$$
\lambda_{t+1}\left(\lambda_{t}, E \lambda_{t+1}\right)=\frac{L_{s, t+1}\left(\lambda_{t}, E \lambda_{t+1}\right)}{L_{t+1}\left(\lambda_{t}\right)}
$$

We discuss each component of this equation in turn.

The population at time $t+1$ is simply the sum over all the children born to households in period $t$. Hence,

$$
L_{t+1}\left(\lambda_{t}\right)=\left[n_{s s}\left(\lambda_{t}\right) \rho_{s s}\left(\lambda_{t}\right)+n_{s u}\left(\lambda_{t}\right) \rho_{s u}\left(\lambda_{t}\right)+n_{u u}\left(\lambda_{t}\right) \rho_{u u}\left(\lambda_{t}\right)\right] L_{t}
$$

where $n_{i j}(\lambda)$ is the utility maximizing number of children for a household with income $I_{i j}(\lambda)$ as indicated in equation (2.2). 
The skilled population at time $t+1$ is simply the sum over all children born to households in period $t$ who decide to become skilled. Recall that some household types may be constrained and hence that the decision to become skilled depends (potentially) both on parental income in period $t$ and hence on $\lambda_{t}$ as well as on payoffs expected for $t+1$ (and hence on $E_{t} \lambda_{t+1}$, where $E$ is the expectations operator). ${ }^{17}$ Thus,

$$
\begin{aligned}
L_{s, t+1}\left(\lambda_{t}, \lambda_{t+1}\right)= & {\left[\pi_{s s}\left(\lambda_{t}, \lambda_{t+1}\right) n_{s s}\left(\lambda_{t}\right) \rho_{s s}\left(\lambda_{t}\right)+\pi_{s u}\left(\lambda_{t}, \lambda_{t+1}\right) n_{s u}\left(\lambda_{t}\right) \rho_{s u}\left(\lambda_{t}\right)\right.} \\
& \left.+\pi_{u u}\left(\lambda_{t}, \lambda_{t+1}\right) n_{u u}\left(\lambda_{t}\right) \rho_{u u}\left(\lambda_{t}\right)\right] L_{t}
\end{aligned}
$$

A steady state is defined as a $\lambda_{t}=\lambda^{*}$ such that $\lambda_{t+1}\left(\lambda^{*}, \lambda_{t+1}\right)=\lambda^{*}$. Note that if $\lambda$ is constant, so are wages, and so is the cutoff quality for a skilled agent to match with an unskilled agent and the education decisions of children.

If the economy had perfect capital markets, then independently of the initial value of $\lambda$, the ability of individuals to borrow implies that a fraction $\widetilde{\lambda}=\Phi(\widetilde{\delta})$ of them will choose to become skilled, i.e. $\pi_{i j}=\widetilde{\lambda}, \forall i j, \forall \lambda_{t}$ such that $\delta^{*}(\widetilde{\lambda})=\widetilde{\delta}$. Thus the economy would converge immediately to the unique steady state.

In the absence of perfect capital markets, the initial distribution of individuals into skilled and unskilled determines the dynamic evolution of the economy. With borrowing constraints, for those family types who are constrained, a fraction smaller than $\Phi\left(\delta^{*}\right)$ will be able to become skilled, and thus in aggregate a fraction that is smaller than $\Phi\left(\delta^{*}\right)$ will become skilled next period. Obviously, the first family type to be constrained will be the $u$ type, followed by the us type and lastly by the ss type, as lower family income implies both more binding borrowing constraints and a larger number of children who wish to borrow.

As shown in Figure 2 for a particular CES production function, this economy can easily give rise to multiple steady states, here given by all the intersections of $\lambda_{t+1}$ with the 45 degree line. ${ }^{18}$ As depicted in the figure, the steady states $A$ and $B$ are locally stable. ${ }^{19}$ The steady state in $A$ is characterized by a low fraction of skilled individuals, high inequality between skilled and unskilled workers,

\footnotetext{
${ }^{17}$ Rational expectations implies that in equilibrium $E_{t} \lambda_{t+1}=\lambda_{t+1}$, so we have suppressed the expectations operator in what follows.

${ }^{18}$ The functional forms used to generate this figure are a production function given by $F\left(L_{s}, L_{u}\right)=\left(\alpha L_{s}^{\gamma}+(1-\alpha) L_{u}^{\gamma}\right)^{1 / \gamma}$, and a limit on aggregate borrowing by children within a family of a fraction $\theta$ of household income, i.e., $Z(I)=\theta I$. Lastly, we assume that $\delta$ is distributed uniformly and that $q$ is distributed with a triangular density function. The parameter values used are: $\alpha=0.2, \gamma=0.5, \theta=0.1 \bar{\delta}=0.2, \bar{q}=8, \beta=0.05, t=0.05$, and $d=0.1$.

${ }^{19}$ Note that the number of locally stable steady states can be greater than two since this
} 
a high degree of sorting in household formation (i.e., skilled individuals predominantly marry other skilled ones; unskilled individuals predominantly marry other unskilled), and large fertility differentials (i.e., $\frac{n_{u u}}{n_{s s}}=\frac{I_{s s}}{I_{u u}}$ is big). In the steady state $B$, the opposite is the case: there is a large fraction of skilled individuals, low inequality, low sorting and low fertility differentials.

Across steady states and indeed across any equilibrium at a point in time, higher inequality is associated with higher sorting. This follows simply from the static analysis in which we showed that greater wage differentials imply greater sorting (Theorem 2.1). We would also have liked to show that (out of steady state) economies that start out with greater inequality end up in a steady state with at least as much inequality, sorting, and fertility differentials than an economy that starts out with lower inequality. This we have confirmed for a large number of simulations but are unable to prove analytically given the endogenous fertility. This does not affect, however, the prediction which we will examine in the data: the existence of a positive correlation between sorting and the skill premium. We now turn to our empirical analysis.

\section{Empirical Analysis}

Our model predicts that countries with higher skill premia should have higher degrees of household sorting. This relationship should hold independently of whether countries have the same technology or whether they are converging to the same or different steady states, since it follows from the static part of our theoretical analysis, in which greater inequality in the incomes of skilled relative to unskilled individuals causes the former to reject a higher proportion of potential matches with unskilled individuals. Furthermore, across steady states, the relationship between sorting and inequality is mutually reinforcing. That is, higher degrees of household sorting should be associated with higher skill premia and vice versa. ${ }^{20}$

The purpose of this section is to establish that there is indeed a positive relationship between marital sorting and the skill premium across countries, and that this relationship is robust with regards to the main concerns that arise with

depends on the change in the fraction of children of different families types that are constrained at different values of $\lambda$.

${ }^{20}$ The second direction of causality though need not hold along the transition path to a steady state. That is, as discussed previously, greater sorting in a given period need not necessarily lead to greater inequality the following period. 
regards to the data or the possible influence of other variables. Although we make a few attempts to establish the direction of causality, our data set does not allow us to identify exogenous variations in either of our two variables of interest and so the main thrust of our empirical analysis is the establishment of a robust correlation between marital sorting and the skill premium. To our knowledge, this is the first paper that has attempted to do so in a systematic fashion for a relatively heterogeneous set of countries. ${ }^{21}$

We examine the main implications of our model using household surveys from 34 countries in various regions of the world. For each country we assemble a sample of households with measures of the education and earnings of both spouses. We then construct several measures of the skill premium for high-skill workers and a measure of the degree of marital sorting by education for each country. We use these measures to examine the correlation between the skill premium and sorting across countries.

We find a positive and significant relation between the skill premium and marital sorting, and show that this finding is robust to controlling for several other variables that can potentially affect the correlation between sorting and the skill premium. If countries have the same technology, our model also predicts that countries with a high degree of sorting should also have a relatively low level of GDP per capita. We find evidence in favor of this negative relationship. Altogether we take these findings to suggest agreement of our basic hypotheses with the data.

\subsection{Sample}

The data consists of a collection of household surveys assembled from the Luxembourg Income Study (LIS) and a collection of Latin-American household surveys held by the Inter-America Development Bank (IDB). From the LIS we obtain wage and education data at the household level for 20 countries, largely European, but also including Australia, Canada, Israel, Taiwan and the U.S. ${ }^{22}$ The years of these surveys ranges from 1990 to 1995. We also include Britain for which we use the British Household Panel Study (1997) rather than the data from the LIS, since in the latter the education variable is reported as the age at the completion of

\footnotetext{
${ }^{21}$ See Dahan and Gavaria (1999) for descriptive evidence on the positive correlation between marital sorting and inequality for Latin American countries.

${ }^{22}$ Education and earnings data for Russia is also available in the LIS, but we choose not to include it due to the low quality of the data. Our basic results hold if Russia is included.
} 
education, a variable that is hard to map into years of schooling. The 13 IDB countries are all located in Latin America and the surveys date from 1996-1997. We provide a more detailed discussion of these household surveys in Appendix B, where we list the names and sample sizes of the surveys by country.

For each country we construct a sample of couples where the husband is between 36 to 45 years old. ${ }^{23}$ We do not restrict the definition of a spouse to legally married couples, but for convenience we refer to them as "wives" and "husbands". We use this sample to construct our measure of marital sorting. Several of our measures of skill premia, on the other hand, incorporate earnings data from a larger age sample of spouses since presumably what individuals care about is some measure of the lifetime income of their spouses rather earnings at a particular point of the life cycle. We include households in the analysis if, in addition to various age requirements, there is a spouse present and education and earnings variables (including zero) are available for both spouses. To avoid problems of income attribution across multiple families within a household, the sample is further restricted to couples where the husband is the head of the household in the Latin-American countries, and to single-family households in the LIS surveys. ${ }^{24}$ We weigh each observation in our calculations by the household weights provided by the household survey.

We use labor income as our measure of the return to education. All the surveys report earnings of each spouse, though the definition of reported income differs by country. Some LIS countries report gross annual labor earnings, all forms of cash wage and salary income, and some report these net of taxes (which is the variable that we would ideally prefer to use). Income in the Latin American countries is gross monthly labor income from all sources. This definition includes income from both primary and secondary labor activities; the exact components vary somewhat across countries, but generally include wages, income from self-employment, and proprietor's income, as well as adjustment to reflect imputation of non-monetary income. Appendix B provides the details of our income measures. The fact that some countries report gross income while others report net income could distort

\footnotetext{
${ }^{23}$ We restrict our attention to this age group for our measure of sorting, since younger cohorts presumably are less stable regarding their marriage patterns. Furthermore, we would ideally prefer to analyze a population for which we can observe both marital decisions and the expectations of lifetime wage inequality at the time of the marriage decision. The latter consideration argues for younger rather than older cohorts since presumably the observed wage inequality corresponds more closely to the expected one than is the case for older individuals.

${ }^{24}$ We were not able to reliably identify all multi-household families in the Latin American surveys, so we cannot explicitly eliminate multi-family households in these countries.
} 
our cross-country comparisons, as net income will be more equally distributed than gross income in those countries with progressive taxation. We discuss our attempt to deal with this problem later on in the paper.

Education measures also differ across countries. While education in the Latin American data is reported either as total years of schooling or, in a few cases as the highest level of education attained, in the LIS countries the education units are quite idiosyncratic. Some countries report years, while others report attainment by country-specific levels. We attempt to standardize the LIS education variable by converting the reported units to years of education. In addition, we create a skill indicator variable that equals 1 if an individual has years of schooling that exceed high-school completion level and equals zero otherwise. This requires us to determine how many years of schooling an individual needs to be able to go beyond high school in each country. The Latin American data also required some standardization because the number of years required for high-school completion varies across countries. For countries that report attainment together with years of schooling, our skill indicator equals 1 if some post-secondary education was reported for an individual. For countries that do not report attainment level, our skill-indicator equals 1 if the years of schooling exceeded the standard time required to complete high school in that country. Our mapping of reported education measures into years of schooling and into an indicator for high school completion is summarized in Table B2 of Appendix B.

\subsection{Variables}

We construct four measures of the skill (education) premium for each country. The first is the ratio of earnings for skilled male workers to unskilled ones in our sorting sample, i.e. husbands between ages 36 and $45 .{ }^{25}$ This measure is very simple and intuitive, and has a direct counterpart in our model. A potential drawback of using the wage ratio as described above is that it reflects income at a particular stage in the life-cycle, and the mapping from this variable to lifetime income is likely to differ across skill groups. It also ignores information other than education that could also affect earnings, such as age or labor market experience. We control for such effects by constructing another measure of the skill premium; this is the coefficient on an indicator for being skilled (i.e., having at least some

\footnotetext{
${ }^{25}$ We focus primarily on the male skill premium as women's labor supply decision is more likely to depend on her spouse's earnings. This is discussed more at length further on in the paper.
} 
post high-school education) in the following regression:

$$
\log \left(e_{i}\right)=a_{0}+a_{1} I_{i}+a_{2}\left(a g e-s_{i}-6\right)+a_{3}\left(a g e-s_{i}-6\right)^{2}+\varepsilon_{i}
$$

where $e_{i}$ is earnings, $I_{i}$ is an indicator for being skilled, $s_{i}$ is years of schooling, and $\left(\right.$ age $\left.-s_{i}-6\right)$ is potential experience for individual- $i$. This regression is estimated for each country by OLS for all husbands aged 30-60 who have positive earnings rather than solely for those aged 36-45. Given that we have controlled for experience, this measure may be able to better capture potential lifetime labor earnings inequality than the simple ratio of earnings for our smaller sample. ${ }^{26}$ We will refer to this measure as the skill indicator measure of inequality and to the previous one as the wage ratio measure of inequality. These two measures will differ as the skill indicator uses a larger sample, omits zero-earnings and controls for experience.

Although these two measures of the skill premium have clear counterparts in our model and hence are easy to interpret, both of these measures depend on our definition of being skilled. Since this definition, i.e. going beyond high school, can be considered rather arbitrary we would like to come up with a measure that does not depend on our particular cutoff. As a widely used measure of returns to schooling, we use the Mincer coefficient as an alternative measure of the skill premium to avoid this problem. The Mincer coefficient is the coefficient on years of schooling in the following regression: ${ }^{27}$

$$
\log \left(e_{i}\right)=b_{0}+b_{1} s_{i}+b_{2}\left(a g e-s_{i}-6\right)+b_{3}\left(a g e-s_{i}-6\right)^{2}+\varepsilon_{i} .
$$

We estimate these regression for all husbands aged 30-60 in our samples, as we did with our skill indicator measure.

Finally, note that our analysis so far has been based on inequality in annual incomes. A better measure, were it available, would be that in expected lifetime incomes, as presumably that is what an individual is thinking about in making a tradeoff between quality and income across matches. In the absence of panel data, we cannot observe lifetime labor incomes. We can, however, create crude

\footnotetext{
${ }^{26}$ How good this measure is of lifetime labor earnings inequality depends on how well the earnings of different cohorts at a point in time represents the lifecycle earnings of an individual (i.e., on the stability of the earnings profile).

${ }^{27}$ These measures will differ from standard Mincer coefficients because we do not control for self-selection bias, and because we estimate the equation on husbands, rather than all workingage males. The correlation of our measures with those tabulated in Bils and Klenow (2000) is 0.57 .
} 
estimates based on the standard 'synthetic cohort' method (Ghez and Becker, 1975). We create projections of lifetime income using observations on older cohorts to predict the future income of the young. ${ }^{28}$ Our simplest measure does this by dividing the life-cycle into 5-year intervals, from 25-30 up to 60-65, then computing average labor income over 5-year intervals for skilled and unskilled individuals separately. We take the present value of the predicted income profiles as the measure of lifetime labor income assuming an annual discount factor of $0.95 .^{29}$ The ratio of these lifetime income measures for skilled relative to unskilled workers constitutes our fourth measure of the skill premium, which we call the lifetime income measure. ${ }^{30}$

Our measure of sorting is the Pearson correlation coefficient between husband's and wife's years of education across couples in our sample. Note that we use education rather than income, although in our model marital sorting occurs in both dimensions (since income is assumed to be a function only of education). We do this because in reality a female's labor force participation decision is often dependent on her spouse's earnings. One might ask, if this is the case, why men would want to marry women with higher education? If the cost of educating children is a function of the mother's education and as long as parents care about having higher-quality children (in the traditional Beckerian fashion), then men will want to match with higher education women because of child quality and women (independently of whether men's education is itself an input into children's quality) will wish to match with more educated men because of the positive relationship between income and education. In our model we have chosen to ignore the greater endogeneity of women's labor force participation decision since it complicates the model and we do not have any particular insights to contribute here as to why these vary across countries.

\footnotetext{
${ }^{28}$ This measure of lifetime income differs from the true measure in so far as the age-income profile varies over time.

${ }^{29}$ We exclude higher ages because some of the age-country-skill cells are empty for particular countries.

${ }^{30} \mathrm{As}$ a further robustness check, we also compute an analogous measure of lifetime income that controls for age variation within cohorts. We estimate the following equation:

$$
y_{i t}=\beta_{0}+\beta_{1} a_{i t}+\beta_{2} a_{i t}^{2}+\beta_{3} a_{i t}^{3}+\gamma_{0} S_{i}+\gamma_{1} S_{i} a_{i t}+\gamma_{2} S_{i} a_{i t}^{2}+\gamma_{3} S_{i} a_{i t}^{3},
$$

where $S_{i}$ is the indicator for being skilled and $a$ is age. We then compute predicted income for each year for each educational class, and as before, take the ratio of the present value of the predicted income profiles as the measure of lifetime labor income inequality. This measure is highly correlated with the first measure.
} 
Table 1 reports the measures of the skill premium and sorting for each country. The first column reports the means and standard deviation of the fraction of skilled husbands in our 36-45 years old husbands sample for each country. The column labelled "Skilled Share" gives the percent of the sample with more than high-school education. The mean level of the share of skilled husbands across countries in our sample is $24.3 \%$ with a standard deviation of around $12.5 \%$. The next four columns show different measures of the skill premium. The average levels of both the wage ratio and of the lifetime income ratio is around 2 with a standard deviation close to 0.8 for the wage ratio and 0.7 for the lifetime income ratio. The means and standard deviations for the skill indicator measure and the Mincer coefficient are $0.67(0.34)$ and 0.095 (0.035), respectively. The last column reports the sample correlation measure of marital sorting. On average across countries, the sample correlation between spouses' years of schooling is about 0.61 with a standard deviation of 0.11 . The countries with the lowest skill premia are Australia and Denmark (wage ratio) and Poland (Mincer coefficient), while Colombia and Brazil (wage ratio) and Bolivia and Paraguay (Mincer coefficient) have the highest. The correlation of the years of schooling across spouses is lowest for Australia, and highest for Colombia and Ecuador. As shown in Table 2, our four measures of the skill premium are highly correlated with each other (over 0.8). All of the correlations are significant at the $1 \%$ level.

\subsection{Results}

This section reports the main results of our empirical analysis. Note first from Table 2 that marital sorting is positively and significantly correlated with all our measures of the skill premium (around 0.6 in each case). Table 3 shows the results from a regression of marital sorting on the skill premium, using our four different measures of the skill premium. The standard errors of the OLS regression are based on the Eicker-White robust covariance matrix in order to correct for heteroskedasticity. For each measure of the skill premium we have included two specifications of the regression. Specification 1 in Table 3 simply regresses sorting on the skill premium. We find that this relationship is positive and significant at the $1 \%$ level for all our measures. Thus, our first empirical test agrees with the basic prediction of our theory of a positive correlation between these two variables.

Figures 3 and 4 show the data used in the regressions of Tables 3 for the wage ratio and the Mincer coefficient measures of the skill premium (the skill indica- 
tor and lifetime income ratio estimates look similar to these). As is clear from these figures, Latin American countries tend to have a greater degree of inequality than the rest of our sample. One possible interpretation of this finding is that the Latin American countries are in a steady state with high inequality and high sorting whereas the rest of our sample (predominantly European countries) are in a low inequality-low sorting steady state with the variation within these subsamples being explained by country-specific factors (e.g., labor-market institutions, education and tax policy, credit markets, etc.). To make sure that our results are not driven by some factor other than sorting that is common to Latin American countries, specification 2 in Table 3 introduces a Latin American dummy variable into the regressions. As can be seen, sorting is still significant, although now at the $5 \%$ level. $^{31}$

We also examined the correlation between marital sorting and the skill premium within our Latin American (LA) and LIS subsamples. For the LIS subsample, the results, as shown in Table 3a, are similar to those of Table 3. .For the LA subsample, the relation although positive is usually not significant, which is not surprising, given the small size of the subsample.

We next examine whether the way variables are reported and how we assign years of education might affect our results. As we have noted previously, some LIS countries report years of education whereas some report only the highest formal level attained, such as high-school diploma or undergraduate degree. As a result, for some countries the years of education or skilled category includes only those who have completed college or the appropriate degree and excludes those who have not obtained the pertinent degree but may have progressed beyond high school. In order to check whether this feature of our data affects our results, the regressions in Table 4 include a dummy variable that takes the value of 1 for countries which report the finer classifications of education and zero otherwise. As Table 4 shows, inclusion of this variable does not affect the sign of the sorting effect (although the significance drops). Furthermore, when the Latin American dummy variable is included, the education-reporting variable has no additional explanatory power and the adjusted R-squared is slightly lower. Again, this is to be expected, as all Latin American countries report years of schooling, which makes the dummy variables very highly correlated.

Another potential concern is that although we have examined each country's education system to understand how it progresses, the actual number of years of

\footnotetext{
${ }^{31}$ We also checked for outliers that shifted the estimated coefficient on the skill premium by more than one standard deviation; there were no outliers.
} 
schooling that we assign to each attainment level may affect our measure of marital sorting. A possible check is to use the Spearman rank correlation between years of schooling of husbands and wives as an alternative measure of sorting. The rank correlation measure of sorting and sample correlation measure are highly correlated (0.98). Our results also go through with this measure, although when a Latin American dummy is introduced the coefficient becomes insignificant for two of our skill premium measures.

As noted previously, some countries report earnings net of taxes and some report gross earnings. Since, due to progressive taxation, gross earnings will in general tend to be more unequal than the net ones, this can create differences in the measured skill premium and affect our results. In order to control for the way income is reported, we introduce a dummy variable that takes a value of 1 if the a country reports net earnings and 0 otherwise. The results are reported in Table 5. The effect of this dummy variable is positive but not significant. As in Table 3 , all four measures of the skill premium still have a positive and significant effect on sorting, indicating that our results were not driven by this particular feature of the data.

\subsection{Other Issues}

In our model the effect of the skill premium on marital sorting is independent of the fraction of the population that is skilled (other than endogenously through the effect of $\lambda$ on the skill premium). This, however, would not be the case in a large set of models in which individuals meet others at random. ${ }^{32}$ Thus, one might expect that a population with a higher $\lambda$, for a given skill premium, would have a greater degree of sorting as skilled individuals (or more educated individuals) know that they have a higher chance of meeting another skilled individual in the future. This would tend to make them less willing to match with an unskilled individual. In Table 6 we examine this issue by controlling for the fraction of skilled individuals in each country in our OLS regression. In all specifications the effect of the skill premium on sorting is positive and significant, at the $1 \%$ level without a Latin American dummy, and at 5 or $10 \%$ with it. ${ }^{33}$ Furthermore, the

\footnotetext{
${ }^{32}$ Even if individuals would for sure be given the opportunity to meet only others from their own skill group in the last period, a model with more than two rounds of matching and discounting would also produce dependence of the cutoff quality level for a mixed match on the fraction of skilled people.

${ }^{33}$ We also controlled for a quadratic relationship in $\lambda$ with similar results.
} 
effect of the population skill level is negative, an issue that we investigate in more detail below.

Although our results in Table 3 indicate a positive and significant correlation between marital sorting and the skill premium, a natural concern is that the correlation is driven by some third factor that is positively correlated with our variables. We next turn to an examination of various possible candidate variables that could be driving our results.

A possible (presumably exogenous) variable that could affect both sorting and the skill premium, it could be argued, is the country's degree of ethnic fractionalization. Note though that the argument must be stronger than the fact that individuals tend to marry others from the same ethnic origin and that for various political economy arguments (e.g. Alesina, Beqir, and Easterly (1999)), countries with greater degrees of ethnic fractionalization have greater degrees of inequality. It must also argue that ethnic groups differ in their human capital so that sorting along ethnic lines translates into sorting along the education dimension. Why this should be so is not clear. One possibility, however, might be the reluctance of an ethnically dominant group to invest in public services (such as schooling) for other ethnic groups (e.g. Easterly (2001)). We examine this issue by introducing a variable that captures the degree of ethno-linguistic fractionalization within the country. This variable, which take values between 0 and 100 with higher values indicating more fractionalization, is taken from World Bank Growth Network (WBGN) data set. ${ }^{34}$ For our set of countries (excluding the Czech Republic, Hungary, Poland and Slovakia for which data was not available) the degree of ethno-linguistic fractionalization ranges from a minimum of 3 (Germany) to a maximum of 75 (Canada) with a mean value of 26.3 and a standard deviation of 20.8 .

Next we consider the possibility that a country's degree of urbanization may be driving our results. Cities, it can be argued, are places where one may expect to have greater mixing among different types than in the countryside where the skill acquisition may tend to be more uniform. Thus, if countries whose population is more concentrated in cities tend to have lower skill premia (perhaps due to better borrowing opportunities in cities), this might be responsible for our finding of a positive correlation between sorting and the skill premium. To examine this hypothesis we introduce an urbanization variable which we take from the WBGN data set as well. This is the fraction of a country's population living in urban areas in 1990 as reported to United Nations by each country. In our sample,

\footnotetext{
${ }^{34}$ This variable is available at http://www.worldbankorg/research/growth/GDNdata.htm
} 
the lowest value for urbanization is 47.1 (Costa Rica) and the highest value is 96.5 (Belgium). Overall, the mean value for urbanization is 73.3 , with a standard deviation of 13.2 .

Another possible concern is that our results are driven by the fraction of labor force that is female. The argument here would have to be something along the lines that in countries in which a greater fraction of woman work, the skill premium is lower (why women's labor force participation should have this effect is rather unclear), and furthermore there is less sorting as men and women from diverse educational backgrounds have greater opportunities to interact (i.e., the workplace) than if women only went to school and then stayed out of the labor force. This would then explain the positive correlation between the skill premium and sorting. We examine this possibility by including a variable that measures the fraction of the labor force that is female. We take the 1990 values of this measure from World Bank (2001). In our sample (Luxemburg and Taiwan are excluded since the data was not available), the lowest value for the fraction of labor force that is female was 27.7 (Ecuador) and the highest was 48 (Finland and Sweden) with a mean of 39.9 and a standard deviation of 6.2.

A last concern is that all our results are driven by the level of GDP per capita. Although GDP per capita is an endogenous variable in our model and hence looking at its exogenous effects is problematic (as we are unable to think of a valid instrument that survives the inclusion of a Latin American dummy), we nonetheless add it as a control (possibly reflecting aspects of income level that are not captured in the model). The argument here would be that countries with low income are more unequal (again, why this follows is not very clear-perhaps a political instability argument related to per capita GDP) and that when income is low, not marrying "down" matters more than when it is high. ${ }^{35}$ Thus, countries with low levels of GDP should also see higher levels of sorting. To evaluate this argument we incorporate a measure of real per capita GDP (its 1997 value from the WBGN) into our regression analysis. The poorest country in our sample has a real GDP per capita of $\$ 1896$ (Bolivia) and the richest one has $\$ 21974$ (Luxembourg), while the average value for the whole sample is $\$ 9897$, with a standard deviation of $\$ 5941 .^{36}$

Table 7 reports the results of introducing each of these variables separately in a regression of marital sorting on the skill premium (using the wage ratio as

\footnotetext{
${ }^{35}$ This argument more generally depends on the the sign of the third derivative of the utility function.

${ }^{36}$ The data for Germany is from 1992.
} 
the measure of the skill premium) as well as introducing them all jointly. As one might expect from our argument above, ethnic fractionalization has a positive and significant effect on marital sorting. The effect of urbanization on sorting is negative but not significant, whereas the faction of labor force that is female has a negative and significant effect on marital sorting. In each specification (both with and without the additional control for Latin American) the coefficient on the skill premium remains positive and significant, although in the cases of urbanization and GDP per capita, the significance drops to the $10 \%$ level when a Latin American dummy is included. In the regression with all the control variables, the positive effect of the skill premium is significant at the $5 \%$ level.

The results from these regressions indicate that the positive correlation between marital sorting and the skill premium is not an artifact either of the ways in which the data is reported nor of some obvious third factor. The positive correlation, nonetheless, does not allow us to determine whether the effect of the skill premium on sorting is truly positive or whether instead this relationship is driven by the potentially positive effect of sorting on the skill premium. We next turn to the question of causality.

In our model both the skill premium and marital sorting are endogenously determined variables. The timing of decisions though is that individuals first sort given the expected skill premium. The effect of current sorting, therefore, is only on future inequality rather than on the current skill premia since how individuals sort affects the proportion of individuals who will be able to become skilled the following generation. Consequently, the skill premium faced by our 35-45 year olds is not simultaneously determined with their sorting patterns. It could be argued, however, that technology shocks that affect the skill premium tend to be serially correlated. If technology shocks are neutral and the production function is constant returns to scale, however, then a measure such as the wage ratio will not be affected by these shocks. On the other hand, if shocks are not neutral then this concern is valid since there will be a bias in the coefficient estimate resulting from the correlation of the explanatory variable with the error term. To correct for this endogeneity bias, we would like to find a variable that is highly correlated with the explanatory variable but not with the error term in the regression equation.

Ex ante, an excellent candidate as an instrument for the skill premium would appear to be the amount of capital per worker, since presumably it would be positively correlated with the skill premium (if we think that capital and skilled labor are more complementary than capital and unskilled labor), and there is no 
reason to believe that it would have an independent effect on the degree of sorting. The problem, however, with this instrument is that it does not capture enough variation across countries beyond those between countries from Latin American and the LIS sample.

As an alternative, we also explored using a variable that measured the strength of labor unions is a potential instrument since it could affect the skill premium but should not have any direct effect on marital sorting. As an instrument, however, it has the same problem as capital per worker. While the strength of labor unions is negatively and significantly correlated with the skill premium, the significant relation disappears once we control for being a LA country. ${ }^{37}$

Another possible instrument for the skill premium is the average years of schooling in a country, since one might expect countries with a higher skilled share of the population (and hence a lower skill premium according to our model) to have higher average years of schooling. Furthermore, this is a variable that evolves slowly over time. According to our model, this variable would not have an effect on sorting other than through its effect on the skill premium. As we discussed above, however, one could easily modify the search portion of our sorting model such that the skilled share of the population (and hence presumably average years of schooling) has an independent effect on marital sorting. As a result, when we use the years of schooling as an instrument, we also include the fraction of skilled population as an additional control.

Table 8 shows our two-stage least squares (2SLS) estimates of the correlation between our different measures of the skill premium and marital sorting. We use the measures of average years of schooling for the population aged 25 and above given in Barro and Lee (2000). Overall, in the first stage regressions without an additional Latin American dummy, both years of schooling and the skilled share of the population are negatively and significantly correlated with different measures of the skill premium (except for with the Mincer coefficient, for which the skilled share has no significant effect). Once we add an additional LA dummy into the first stage regressions, the effect of the skilled share diminishes, possibly reflecting the fact that LA countries in general have a lower skilled share.

In the second stage regressions, the effect of the skill premium on marital sorting is positive and highly significant. Furthermore, as expected, the effect of the skilled share of the population on marital sorting is positive. Indeed, the

\footnotetext{
${ }^{37}$ We used total trade union membership as a percentage of the total labor force and workers covered by collective bargaining as a percentage of total salaried workers as two different measures of the strength of unions (data from Rama and Arcetona (2000))
} 
estimates of the effect of the skill premium on marital sorting are significantly larger than the ones we obtained from OLS. The estimate of 0.15 on the wage ratio, for example, implies that going from a more equal country like Sweden to an unequal one like Chile results in an increase in the correlation coefficient for spouses education of about 0.31 points. The fact that the effect of being a Latin American country on marital sorting is negative indicates that once we account for the skill premium, Latin American countries tend to have lower marital sorting, a result that is rather hard to interpret in light of our previous finding of a positive coefficient on this dummy variable. Finally, the finding of larger estimates on our various measures of the skill premium in the IV regressions above might suggest that downward bias due to measurement error in the skill premium might be larger than the potential reverse causality problem.

A potential problem with our instrument, however, is that one could imagine that years of schooling might have an independent (presumably negative) effect on sorting by allowing people to mix for a greater amount of time before finally separating across skill lines. This consideration suggests that our IV results should be approached with some caution. ${ }^{38}$

\subsection{Per Capita Income, Skilled Population and Sorting}

We now turn to an examination of another prediction of our model: the existence of a negative relation between marital sorting and per capita income across countries. Note that our model implies that across steady states, economies (with the same technology) are characterized by a positive relationship between sorting and the skill premium and a negative relationship of these with the fraction of skilled individuals. Consequently, ceteris paribus, we expect economies with similar technologies but with greater sorting to have lower per capita income as their level of human capital will be further below the efficient level. We turn to an examination of this relationship in the data.

Figure 6 shows the relation between marital sorting and per capita income where per capita income is real GDP per capita in 1997. Note that although per capita output is an endogenous variable in our model, the timing is such that sorting will affect future output (rather than being affected by it). Table 9 shows the regression results for a specification in which the dependent variable is our measure of per capita income and the explanatory variable is the sample correlation measure of marital sorting with and without a Latin American dummy.

\footnotetext{
${ }^{38}$ We thank Torsten Persson for bringing this point to our attention.
} 
The relation is significant and negative for both specifications as predicted by our model.

\section{Conclusion}

This paper has examined the relationship between marital or household sorting and income inequality. Using a general equilibrium model in which individuals make decisions over whether to become skilled or unskilled, about with whom to match, how much to consume, and the number of children to have, we find that there is a positive relationship between sorting and inequality (between skilled and unskilled workers). In particular, whether at a point in time, or across steady states, economies with greater skill premia should also display a greater degree of sorting. Our model also predicts that economies with greater skill premia should have greater fertility differentials, and (given identical technologies) economies with greater sorting should have lower per capita income and smaller fractions of skilled workers.

Our empirical work is based on household surveys for 34 countries. From these surveys we create our main sample for each country, a measure of marital sorting, and various measures of the skill premium. Our regression analysis supports our central prediction of a positive relationship between sorting and inequality across countries even after controlling for other possible sources of this correlation. We also find evidence in favor of a negative relationship between sorting and per capita income as predicted by our model as well.

It should be noted that our story of greater pickiness with respect to household partners in the face of an increased skill premium is of course not the only one compatible with a positive correlation between these two variables. An alternative story, with similar mechanics, would be of greater sorting into communities or schools in response to greater inequality (say, in response to fear of more crime). This could then lead to fewer opportunities to interact between individuals of different skill groups and consequently to a greater correlation of spouses in education. We do not see this mechanism as being very different. Once again, private decisions that are sensitive to the degree of inequality (e.g., where to live, where to go to school) would feed through to marital decisions, which would then have important social consequences as a result of borrowing constraints.

There are many directions in which this work could be extended. We have abstracted from several issues, each of which are of interest in their own right. First, we have ignored differences between men and women. An alternative formulation 
of our model would be to have parents care about the quality and quantity of their children and for parental time and education to be a factor in producing quality (perhaps by lowering the cost of the children becoming skilled). Thus, a parent who stayed at home and took care of the children would contribute to household utility by increasing the quality of their offspring. If, because of childbearing costs this were predominantly the woman, men would still wish to match with more educated women either because of their earning potential (as in the model) or because of the increased quality of the children. Thus, a major topic we wish to investigate (theoretically and empirically) is the relationship among sorting, female wage inequality and male wage inequality. ${ }^{39}$ This would also tie in with another set of issues that we have chosen to ignore-that of household bargaining, the option to remain single and the possibility of divorce. Another avenue to explore is the importance of bequests relative to education in the intergenerational transmission of inequality. Lastly, it would be interesting to examine the role of public policy (education subsidies and welfare policy) in interacting with sorting and inequality. We plan to study several of these issues in future work.

\footnotetext{
${ }^{39}$ See Galor and Weil (1996) for a model in which exogenous differences between women and men leads to a large gap between the wages of these at low levels of capital, which is then reduced as capital accumulates. They use this model to help explain the demographic transition.
} 


\section{References}

[1] Aiyagari, S. Rao, J. Greenwood, and N. Guner. "On the State of the Union." Journal of Political Economy, 108 (2000), 213-244.

[2] Alesina, Alberto, R. Baqir, and W. Easterly, "Public Goods and Ethnic Divisions," Quarterly Journal of Economics, CXIV (1999), 1243-1284.

[3] Barro, Robert J. and J. W. Lee, "International Data on Educational Attainments: Updates and Implications," mimeo, (2000).

[4] Becker, Gary S. "A Theory of Marriage: Part I," Journal of Political Economy, 81 (1973): 813-846.

[5] Becker, Gary S. and N. Tomes, "An Equilibrium Theory of the Distribution of Income and Intergenerational Mobility," Journal of Political Economy, 87 (1979), 1153-1189.

[6] _. . . . . . ., "Human Capital and the Rise and Fall of Families," Journal of Labor Economics, 4 (1986), S1-S39.

[7] Bénabou, Roland, "Heterogeneity, Stratification and Growth," American Economic Review, 86 (1996), 584-609.

[8] Bergstrom, Theodore C., "A Survey of Theories of The Family," in Handbook of Population and Family Economics, Edited by M. R. Rosenzweig and O. Stark, Elsevier Science, 1997.

[9] Bils, Mark and P. J. Klenow, "Does Schooling Cause Growth?" American Economic Review, 90 (2000), 1160-1183.

[10] Boulier, Bryan L. and M. R. Rosenzweig, "Schooling, Search, and Spouse Selection: Testing Economic Theories of Marriage and Household Behavior," Journal of Political Economy, 92 (1984), 712-732.

[11] Burdett, Kenneth and M. G. Coles, "Marriage and Class," Quarterly Journal of Economics, 112, (1997), 141-168.

[12] _ _ _ _ _ _, "Transplants and Implants: The Economics of SelfImprovement," mimeo, (1999). 
[13] Cole, Harold L., G. Mailath, and A. Postlewaite, "Social Norms, Savings Behavior and Growth," Journal of Political Economy, 100 (1992), 1092-1125.

[14] Dahan, Momi and D. Tsiddon, "Demographic Transition, Income Distribution and Economic Growth," Journal of Economic Growth, 3 (1998), 29-52.

[15] Dahan, Momi and A. Gaviria, "Sibling Correlations and Intergenerational Mobility in Latin America," mimeo, (1999).

[16] Durlauf, S., "A Theory of Persistent Income Inequality," Journal of Economic Growth, 1 (1995), 75-93.

[17] Easterly, William, "The Middle Class Consensus and Economic Development," mimeo, 2001.

[18] Fernández, Raquel, "Education, Segregation, and Marital Sorting: Theory and an Application to the UK," mimeo, (2001).

[19] Fernández, Raquel and C. A. Pissarides, "Searching for a Partner," mimeo, (2001).

[20] Fernández, Raquel and R. Rogerson, "Public Education and Income Distribution: A Dynamic Quantitative Evaluation of Education Finance Reform," American Economic Review, 88 (1998), 813-833.

[21] _ . . . . . . , "Sorting and Long-Run Inequality," Quarterly Journal of Economics, forthcoming, (2001).

[22] Galor, Oded and J. Zeira, "Income Distribution and Macroeconomics," Review of Economic Studies, 60 (1993), 35-52.

[23] Galor, Oded and D. Weil, "The Gender Gap, Fertility and Growth," American Economic Review, 86 (1996), 374-387.

[24] Greenwood, Jeremy, N. Guner and J. Knowles, "More on Marriage, Fertility and the Distribution of Income," mimeo, (1999).

[25] Knowles, John, "Can Parental Decisions Explain U.S. Income Inequality?" PhD Dissertation, University of Rochester, (1999).

[26] Kremer, Michael, "How Much does Sorting Increase Inequality," Quarterly Journal of Economics, 112 (1997), 115-139. 
[27] Kremer, Michael and D. Chen, "Income Distribution Dynamics with Endogenous Fertility," American Economic Review Papers and Proceedings, 89 (1999), 155-160.

[28] Laitner, John, "Household Bequests, Perfect Expectations, and the National Distribution of Wealth," Econometrica, 47 (5), (1979), 1175-1194.

[29] Lam, David, "Marriage Markets and Assortative Mating with Household Public Goods: Theoretical Results and Empirical Implications," Journal of Human Resources, 23 (1988), 462-487.

[30] Ljungqvist, Lars, "Economic Development: The Case of a Missing Market for Human Capital," Journal of Development Economics, 40 (1993), 219-239.

[31] Loury, Glenn C. "Intergenerational Transfers and the Distribution of Earnings." Econometrica, 49 (1981), 843-867.

[32] Mare, Robert D. "Five Decades of Educational Assortative Mating," American Journal of Sociology, 56, (1991), 15-32.

[33] Owen, Ann and D. Weil, "Intergenerational Earnings Mobility, Inequality and Growth," Journal of Monetary Economics, 41 (1998), 71-104.

[34] Perotti, Roberto, "Growth, Income Distribution, and Democracy: What the Data Say," Journal of Economic Growth, 1 (1996), 149-187.

[35] Pissarides, Chris, "From School to University: The Demand for PostCompulsory Education in Britain," Economic Journal, 92 (1982), 654-667.

[36] Rama, Martin and R. Artecona. "A Database of Labor Market Indicators Across Countries," The World Bank, mimeo (2000).

[37] Regalia, Ferdinando and J. V. Rios-Rull. "What Accounts for the Increase in Single Households and the Stability in Fertility?" mimeo (1999).

[38] Smits, Jeroen, W. Ultee, and J. Lammers, "Educational Homogamy in 65 Countries: An Explanation of Differences in Openness Using Country-Level Explanatory Variables," American Sociological Review, 63 (1998), 264-285. 
[39] Weiss, Yoram. "The Formation and Dissolution of Families: Why Marry? Who Marries Whom? and What Happens upon Divorce?" in Handbook of Population and Family Economics, Edited by M. R. Rosenzweig and O. Stark, Elsevier Science, 1997.

[40] World Bank, World Development Indicators, 2001.

\section{Appendix A}

We will now show that all terms in the first curly bracket of equation (2.18) Before doing this, as we have already argued, $\frac{\partial q^{*}}{\partial \lambda}$ is strictly negative, since

$$
\frac{\partial q^{*}}{\partial \lambda}=\underbrace{\frac{f^{\prime \prime}}{f^{\prime}\left(f^{\prime}(1-k)+f\right)}}_{-}[\underbrace{\left(\widetilde{w}_{s}-w_{u}\right)}_{+}+f^{\prime}(1+k) \underbrace{\left(w_{u}+\widetilde{w}_{s}-\beta\right)}_{+}] \frac{1}{(1-\lambda)^{2}}<0
$$

where $f^{\prime}\left(f^{\prime}(1-k)+f\right)=\widetilde{w}_{s}\left(\widetilde{w}_{s}+w_{u}\right)>0$. Hence, all we want to determine is the sign of the following expression

$$
\begin{aligned}
A= & \left\{\left[\left(1+2 k Q^{*}+k^{2}\right)\left(\widetilde{w}_{s}+w_{u}-\beta\right)+\left(2 k+Q^{*} k^{2}+Q^{*}\right)\left(\widetilde{w}_{s}+w_{u}\right)\right] \widetilde{w}_{s} w_{u}\right. \\
& \left.-\beta\left(k+Q^{*}\right) w_{u}^{2}-\beta\left(k+k^{2} Q^{*}\right) \widetilde{w}_{s}^{2}\right\},
\end{aligned}
$$

where $Q^{*}=Q\left(q^{*}\right)$.

Note that if $w_{u} \geq \beta$, then we are all set, since then

$$
\left(2 k+Q^{*} k^{2}+Q^{*}\right) \widetilde{w}_{s}^{2} w_{u}-\beta\left(k+k^{2} Q^{*}\right) \widetilde{w}_{s}>0,
$$

and

$$
\left(2 k+Q^{*} k^{2}+Q^{*}\right) w_{u}^{2} w_{s}-\beta\left(k+Q^{*}\right) w_{u}^{2}>0 .
$$

Therefore, we only need to take care of the case where $w_{u}<\beta$.

In order to show that the following expression

$$
\begin{aligned}
A= & \left\{\left[\left(1+2 k Q^{*}+k^{2}\right)\left(\widetilde{w}_{s}+w_{u}-\beta\right)+\left(2 k+Q^{*} k^{2}+Q^{*}\right)\left(\widetilde{w}_{s}+w_{u}\right)\right] \widetilde{w}_{s} w_{u}\right. \\
& \left.-\beta\left(k+Q^{*}\right) w_{u}^{2}-\beta\left(k+k^{2} Q^{*}\right) \widetilde{w}_{s}^{2}\right\},
\end{aligned}
$$

is positive for $w_{u}<\beta$, we will simply show that it is increasing in $w_{u}$ and $\widetilde{w}_{s}$ and when evaluated at $w_{u}=\widetilde{w}_{s}=\frac{\beta}{2}$, it is non-negative (recall that $w_{u} \geq \frac{\beta}{2}$ and 
$\left.w_{u} \geq \frac{\beta}{2}\right)$. We start by showing that $A$ is increasing in $w_{u}$ for $w_{u}<\beta$. In order to do this, let take the derivative of $A$ with respect to $w_{u}$ to get

$$
\begin{aligned}
\frac{\partial A}{\partial w_{u}}= & \left(1+2 k Q^{*}+k^{2}\right)\left(\widetilde{w}_{s}^{2}+2 w_{s} w_{u}-\beta \widetilde{w}_{s}\right) \\
& +\left(2 k+Q^{*} k^{2}+Q^{*}\right)\left(2 \widetilde{w}_{s} w_{u}+\widetilde{w}_{s}^{2}\right)-2 \beta\left(k+Q^{*}\right) w_{u} .
\end{aligned}
$$

Note that this expression is increasing in $\widetilde{w}_{s}$ (since $\widetilde{w}_{s} \geq \frac{\beta}{2}$ ), and we can evaluate it at the limit where $\widetilde{w}_{s}=\frac{\beta}{2}$ to get

$$
\begin{aligned}
\left.\frac{\partial A}{\partial w_{u}}\right|_{\widetilde{w}_{s}=\frac{\beta}{2}}= & \beta w_{u}\left(1+2 k Q^{*}+k^{2}+2 k+Q^{*} k^{2}+Q^{*}-2 k-2 Q^{*}\right) \\
& +\frac{\beta^{2}}{4}\left(2 k+Q^{*} k^{2}+Q^{*}-1-2 k Q^{*}-k^{2}\right) .
\end{aligned}
$$

This expression is also increasing in $w_{u}$ (since $1 \geq Q$ ), and hence we can also evaluate it at $w_{u}=\frac{\beta}{2}$ (recall that $w_{u} \geq \frac{\beta}{2}$ ) to get

$$
\left.\frac{\partial A}{\partial w_{u}}\right|_{\widetilde{w}_{s}=\frac{\beta}{2}, w_{u}=\frac{\beta}{2}}=\beta^{2}\left(\frac{1}{4}+\frac{1}{2} k Q^{*}+\frac{1}{4} k^{2}-\frac{1}{4} Q^{*}+\frac{3}{4} Q^{*} k^{2}+\frac{1}{2} k\right)>0 .
$$

Therefore, $A$ is indeed increasing in $w_{u}$.

We next will show that $A$ is increasing in $\widetilde{w}_{s}$. Taking the derivative with respect to $\widetilde{w}_{s}$ we get

$$
\begin{aligned}
\frac{\partial A}{\partial \widetilde{w}_{s}}= & \left(1+2 k Q^{*}+k^{2}\right)\left(2 \widetilde{w}_{s} w_{u}+\widetilde{w}_{u}^{2}-\beta w_{u}\right) \\
& +\left(2 k+Q^{*} k^{2}+Q^{*}\right)\left(2 \widetilde{w}_{s} w_{u}+w_{u}^{2}\right)-2 \beta\left(k+k^{2} Q^{*}\right) \widetilde{w}_{s}
\end{aligned}
$$

Since $w_{u} \geq \frac{\beta}{2}$, this expression is increasing in $w_{u}$, and we can evaluate at the limit where $w_{u}=\frac{\beta}{2}$,

$$
\begin{aligned}
\left.\frac{\partial A}{\partial \widetilde{w}_{s}}\right|_{w_{u}=\frac{\beta}{2}}= & \left(1+2 k Q^{*}+k^{2}\right)\left(\beta \widetilde{w}_{s}-\frac{\beta^{2}}{4}\right) \\
& +\left(2 k+Q^{*} k^{2}+Q^{*}\right)\left(\beta \widetilde{w}_{s}+\frac{\beta^{2}}{4}\right)-2 \beta\left(k+k^{2} Q^{*}\right) \widetilde{w}_{s} .
\end{aligned}
$$


Again, this expression is also increasing in $\widetilde{w}_{s}$ (note that $Q \leq 1$ ), therefore we can evaluate it at $\widetilde{w}_{s}=\frac{\beta}{2}$,

$$
\left.\frac{\partial A}{\partial \widetilde{w}_{s}}\right|_{\widetilde{w}_{s}=\frac{\beta}{2}, w_{u}=\frac{\beta}{2}}=\left(1+2 k Q^{*}+k^{2}\right) \frac{\beta^{2}}{4}+\frac{3 \beta^{2}}{4}\left(2 k+Q^{*} k^{2}+Q^{*}\right)-\left(k+k^{2} Q^{*}\right) \beta^{2}>0 .
$$

Thus $A$ is increasing in $\widetilde{w}_{s}$ and $w_{u}$. To show that $A$ is positive, we simply evaluate it at $\widetilde{w}_{s}=w_{u}=\frac{\beta}{2}$ :

$$
\left.A\right|_{\widetilde{w}_{s}=\frac{\beta}{2}, w_{u}=\frac{\beta}{2}}=0+\left(2 k+Q^{*} k^{2}+Q^{*}\right) \frac{\beta^{3}}{4}-\left(k+Q^{*}\right) \frac{\beta^{3}}{4}-\left(k+k^{2} Q^{*}\right) \frac{\beta^{3}}{4}=0
$$

Hence, in Equation (2.18) all terms are negative except those with $\frac{\partial \lambda}{\partial k}$.

\section{Appendix B}

The years of households surveys used in our empirical study are given in Table B1. All surveys are nationally representative samples, except for Argentina and Uruguay for which we have only urban samples (70\% of the population for Argentina and 90\% for Uruguay). Table B1 also gives details of the income measures available in each survey. The income in the Latin American countries is gross monthly labor income from all sources. This definition varies across countries, but generally includes wages, income from self-employment, proprietor's income, from both primary and secondary labor activities. Some LIS countries report gross annual earnings and income and some report these net of taxes. ${ }^{40}$ We use gross labor earnings for LIS countries whenever it is available. The gross earnings measure for LIS countries include all forms of cash wage and salary income, including employer bonuses, 13th month bonus, etc., (gross of employee social insurance contributions/taxes but net of employer social insurance contributions/taxes). While most countries report gross earnings, the following countries report only the net earnings: Belgium, France, Hungary, Italy, Luxemburg, Poland, and Spain. Since taxation tends to be progressive in the countries we are comparing, inequality of income is likely to be higher than reported in those countries for which pre-tax income is not reported. We do not adjust income measures in LIS or IDB for

\footnotetext{
${ }^{40}$ Some LIS countries are excluded because they do not report all of the variables required for the analysis. Ireland and Austria do not report individual labor income. Ireland also does not report the education of the spouse in the household sample. Education variables are not available for Switzerland.
} 
hours worked or weeks worked in order to arrive at a measure of total income, including leisure. This is because few countries collect hours or weeks series, and some of those that do collect them, such as Slovakia or Spain, use discrete codes rather then report actual levels.

Education in the Latin American data is reported as total years of schooling. For the LIS countries the education units are quite idiosyncratic. We attempt to standardize the LIS education variable by converting the reported units to years of education. We define as skilled all agents who went beyond high school education. For some of the Latin-American data, this coincides with indicator variables for higher education, as a few of these countries report attainment in addition to years of education. For the other Latin-America countries, this indicator is constructed using the standard age-grade progression for that country. Thus, skilled workers in Costa Rica, for example, are those with more than 11 years of education, while in Mexico, they are those with more than 12 years. For Britain we would have preferred to define as skilled any individual with at least $2 \mathrm{~A}$ levels passes (as in Fernández (2001) or Pissarides (1982)), but as the data did not permit us to distinguish among individuals with different number of A levels, we instead categorized them all as unskilled. Our results are robust to categorizing them all as skilled instead. Table B2 reports our mapping of education measures into years of schooling and into an indicator for high school completions. For most countries, we were able to compare the percentage of adults with education beyond the highschool level to published sources, and to reconcile our statistics with the previously published numbers. 
Figure 1
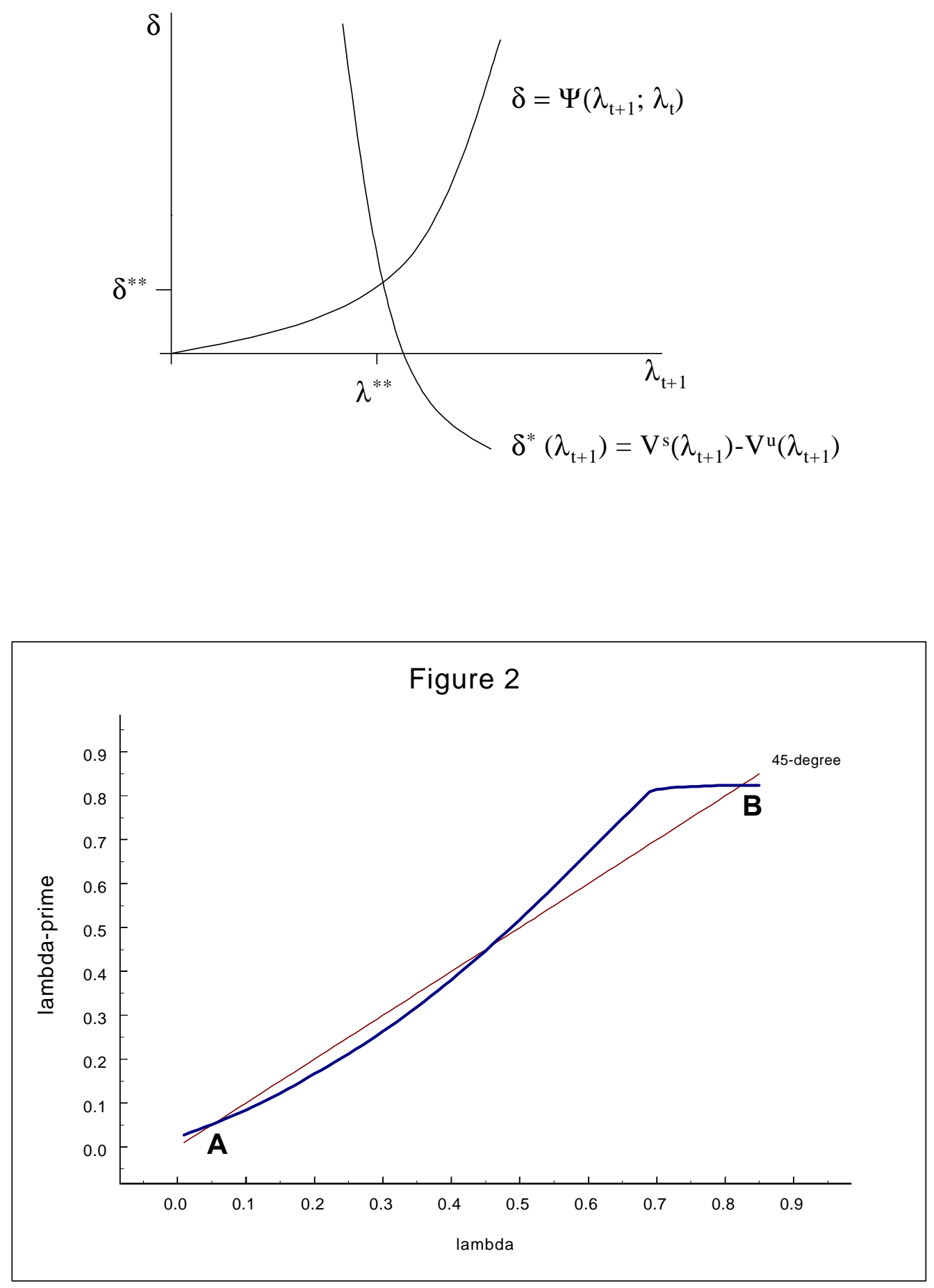

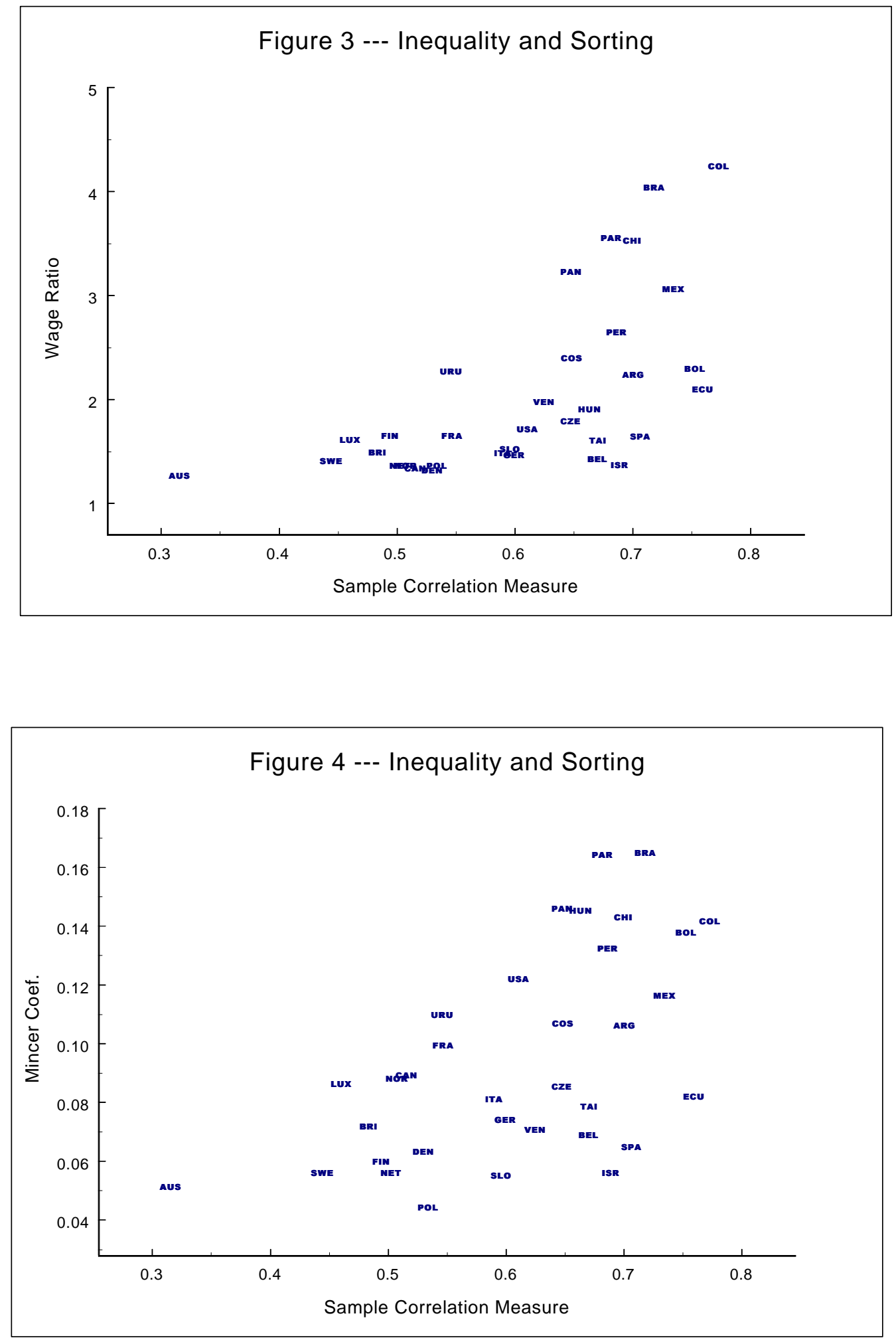


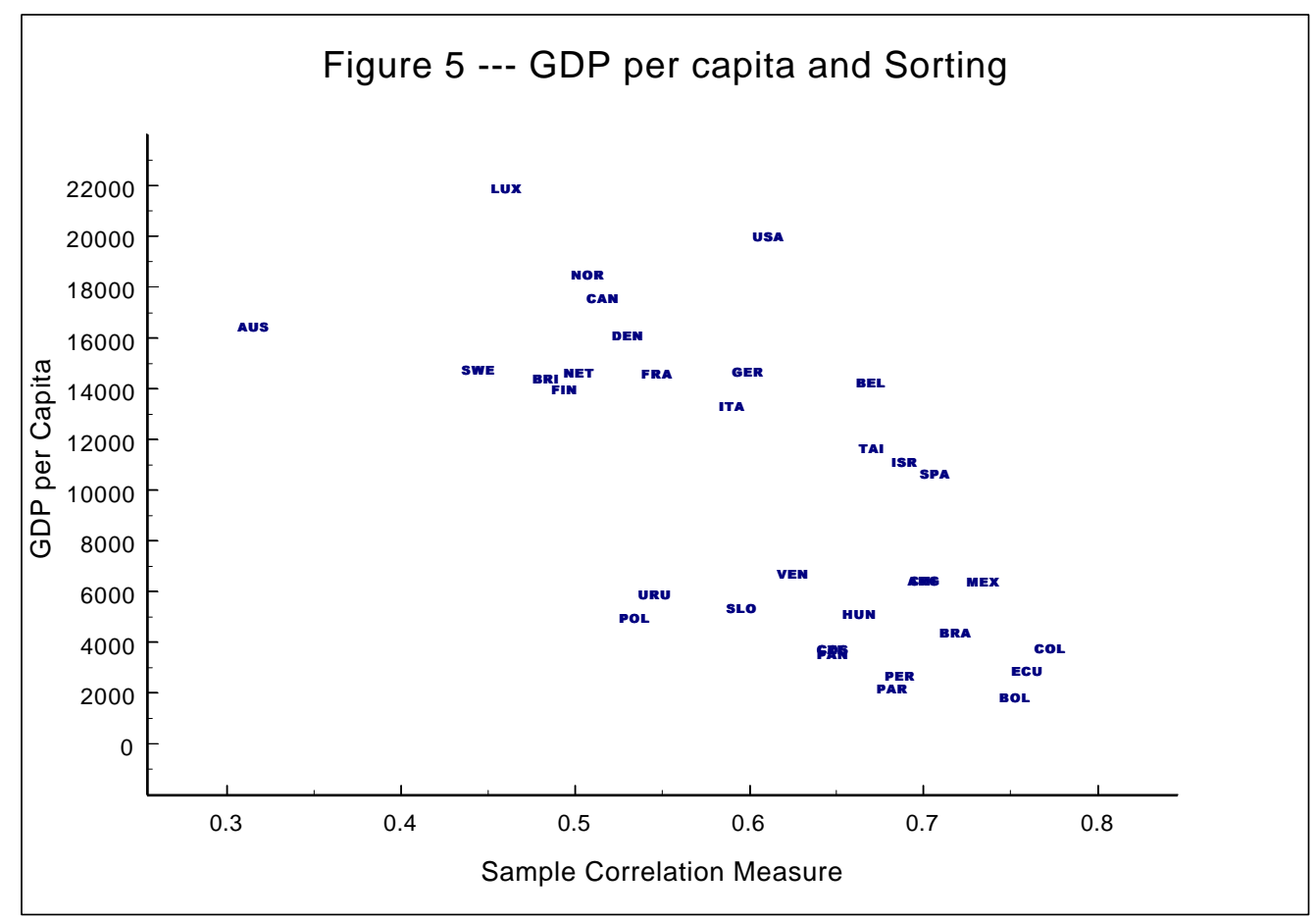




\begin{tabular}{|c|c|c|c|c|c|c|c|}
\hline \multirow[t]{2}{*}{ Country } & \multirow[t]{2}{*}{ Statistic } & \multirow{2}{*}{$\begin{array}{c}\text { Skilled Share } \\
\text { Husbands }\end{array}$} & \multicolumn{4}{|c|}{ Skill Premium } & \multirow{2}{*}{$\begin{array}{c}\text { Marital Sorting } \\
\text { Pearson Correlation }\end{array}$} \\
\hline & & & Wage Ratio & Skill Indicator & Mincer Coef. & Lifetime Ratio & \\
\hline Argentina & $\begin{array}{l}\text { mean } \\
\text { std. }\end{array}$ & $\begin{array}{c}0.189 \\
(0.392) \\
\end{array}$ & $\begin{array}{c}2.249 \\
(0.165) \\
\end{array}$ & $\begin{array}{c}0.872 \\
(0.017) \\
\end{array}$ & $\begin{array}{c}0.107 \\
(0.002) \\
\end{array}$ & $\begin{array}{c}2.090 \\
. \\
\end{array}$ & $\begin{array}{c}0.700 \\
.\end{array}$ \\
\hline Australia & $\begin{array}{l}\text { mean } \\
\text { std. }\end{array}$ & $\begin{array}{c}0.303 \\
(0.459)\end{array}$ & $\begin{array}{l}1.277 \\
(0.034)\end{array}$ & $\begin{array}{c}0.308 \\
(0.035)\end{array}$ & $\begin{array}{c}0.052 \\
(0.005)\end{array}$ & $\begin{array}{c}1.298 \\
.\end{array}$ & $\begin{array}{c}0.315 \\
.\end{array}$ \\
\hline Belgium & $\begin{array}{l}\text { mean } \\
\text { std. }\end{array}$ & $\begin{array}{c}0.295 \\
(0.456) \\
\end{array}$ & $\begin{array}{c}1.437 \\
(0.031) \\
\end{array}$ & $\begin{array}{l}1.087 \\
(0.052) \\
\end{array}$ & $\begin{array}{c}0.138 \\
(0.004) \\
\end{array}$ & 1.390 & 0.670 \\
\hline Bolivia & $\begin{array}{l}\text { mean } \\
\text { std. }\end{array}$ & $\begin{array}{c}0.172 \\
(0.377) \\
\end{array}$ & $\begin{array}{l}2.306 \\
(2.161) \\
\end{array}$ & $\begin{array}{c}1.472 \\
(0.017) \\
\end{array}$ & $\begin{array}{c}0.165 \\
(0.001) \\
\end{array}$ & 2.440 & $\begin{array}{c}0.752 \\
.\end{array}$ \\
\hline Brasil & $\begin{array}{l}\text { mean } \\
\text { std. }\end{array}$ & $\begin{array}{c}0.105 \\
(0.306) \\
\end{array}$ & $\begin{array}{c}4.050 \\
(1.886) \\
\end{array}$ & $\begin{array}{c}0.416 \\
(0.026) \\
\end{array}$ & $\begin{array}{c}0.069 \\
(0.004) \\
\end{array}$ & 3.810 & $\begin{array}{c}0.718 \\
.\end{array}$ \\
\hline Britain & $\begin{array}{l}\text { mean } \\
\text { std. }\end{array}$ & $\begin{array}{c}0.440 \\
(0.496) \\
\end{array}$ & $\begin{array}{l}1.499 \\
(0.002) \\
\end{array}$ & $\begin{array}{c}0.292 \\
(0.041) \\
\end{array}$ & $\begin{array}{c}0.072 \\
(0.008) \\
\end{array}$ & $\begin{array}{c}1.319 \\
.\end{array}$ & $\begin{array}{c}0.483 \\
.\end{array}$ \\
\hline Canada & $\begin{array}{l}\text { mean } \\
\text { std. }\end{array}$ & $\begin{array}{l}0.597 \\
0.490 \\
\end{array}$ & $\begin{array}{c}1.348 \\
(0.227) \\
\end{array}$ & $\begin{array}{c}1.215 \\
(0.019) \\
\end{array}$ & $\begin{array}{c}0.144 \\
(0.002) \\
\end{array}$ & 1.328 & $\begin{array}{c}0.516 \\
.\end{array}$ \\
\hline Chile & $\begin{array}{l}\text { mean } \\
\text { std. }\end{array}$ & $\begin{array}{l}0.149 \\
0.356\end{array}$ & $\begin{array}{c}3.538 \\
(0.261) \\
\end{array}$ & $\begin{array}{c}1.276 \\
(0.023)\end{array}$ & $\begin{array}{c}0.142 \\
(0.002)\end{array}$ & 3.226 & 0.700 \\
\hline Colombia & $\begin{array}{l}\text { mean } \\
\text { std. }\end{array}$ & $\begin{array}{c}0.150 \\
(0.357) \\
\end{array}$ & $\begin{array}{c}4.259 \\
(18.337) \\
\end{array}$ & $\begin{array}{c}0.904 \\
(0.037) \\
\end{array}$ & $\begin{array}{c}0.107 \\
(0.003) \\
\end{array}$ & $\begin{array}{c}3.617 \\
.\end{array}$ & $\begin{array}{c}0.772 \\
.\end{array}$ \\
\hline Costa Rica & $\begin{array}{l}\text { mean } \\
\text { std. }\end{array}$ & $\begin{array}{c}0.150 \\
(0.358) \\
\end{array}$ & $\begin{array}{c}2.408 \\
(0.753) \\
\end{array}$ & $\begin{array}{c}0.310 \\
(0.014) \\
\end{array}$ & $\begin{array}{c}0.090 \\
(0.003) \\
\end{array}$ & 2.379 & 0.648 \\
\hline Czech & $\begin{array}{l}\text { mean } \\
\text { std. }\end{array}$ & $\begin{array}{c}0.153 \\
(0.360) \\
\end{array}$ & $\begin{array}{c}1.803 \\
(0.283) \\
\end{array}$ & $\begin{array}{c}0.528 \\
(0.014) \\
\end{array}$ & $\begin{array}{c}0.086 \\
(0.002) \\
\end{array}$ & 1.652 & 0.647 \\
\hline Denmark & $\begin{array}{l}\text { mean } \\
\text { std. }\end{array}$ & $\begin{array}{c}0.302 \\
(0.459) \\
\end{array}$ & $\begin{array}{c}1.331 \\
(0.024)\end{array}$ & $\begin{array}{c}0.415 \\
(0.034)\end{array}$ & $\begin{array}{c}0.064 \\
(0.005)\end{array}$ & $\begin{array}{c}1.460 \\
.\end{array}$ & $\begin{array}{c}0.530 \\
.\end{array}$ \\
\hline Ecuador & $\begin{array}{l}\text { mean } \\
\text { std. }\end{array}$ & $\begin{array}{c}0.277 \\
(0.447) \\
\end{array}$ & $\begin{array}{c}2.106 \\
(0.117) \\
\end{array}$ & $\begin{array}{c}0.730 \\
(0.028) \\
\end{array}$ & $\begin{array}{c}0.082 \\
(0.002) \\
\end{array}$ & $\begin{array}{c}2.206 \\
.\end{array}$ & $\begin{array}{c}0.759 \\
.\end{array}$ \\
\hline Finland & $\begin{array}{l}\text { mean } \\
\text { std. }\end{array}$ & $\begin{array}{c}0.273 \\
(0.445) \\
\end{array}$ & $\begin{array}{c}1.666 \\
(0.003) \\
\end{array}$ & $\begin{array}{c}0.605 \\
(0.049) \\
\end{array}$ & $\begin{array}{c}0.060 \\
(0.006) \\
\end{array}$ & $\begin{array}{c}1.724 \\
. \\
\end{array}$ & $\begin{array}{c}0.494 \\
.\end{array}$ \\
\hline France & $\begin{array}{l}\text { mean } \\
\text { std. }\end{array}$ & $\begin{array}{c}0.271 \\
(0.445) \\
\end{array}$ & $\begin{array}{c}1.662 \\
(0.048) \\
\end{array}$ & $\begin{array}{c}0.543 \\
(0.032) \\
\end{array}$ & $\begin{array}{c}0.100 \\
(0.005) \\
\end{array}$ & 1.708 & $\begin{array}{c}0.546 \\
.\end{array}$ \\
\hline Germany & $\begin{array}{l}\text { mean } \\
\text { std. }\end{array}$ & $\begin{array}{c}0.275 \\
(0.447) \\
\end{array}$ & $\begin{array}{c}1.480 \\
(0.023) \\
\end{array}$ & $\begin{array}{c}0.376 \\
(0.034) \\
\end{array}$ & $\begin{array}{c}0.074 \\
(0.006) \\
\end{array}$ & 1.332 & 0.599 \\
\hline Hungary & $\begin{array}{l}\text { mean } \\
\text { std. }\end{array}$ & $\begin{array}{c}0.163 \\
(0.370) \\
\end{array}$ & $\begin{array}{c}1.921 \\
(0.151) \\
\end{array}$ & $\begin{array}{c}0.735 \\
(0.060) \\
\end{array}$ & $\begin{array}{c}0.146 \\
(0.010) \\
\end{array}$ & 2.078 & $\begin{array}{c}0.663 \\
. \\
\end{array}$ \\
\hline Israel & $\begin{array}{l}\text { mean } \\
\text { std. }\end{array}$ & $\begin{array}{c}0.426 \\
(0.494) \\
\end{array}$ & $\begin{array}{c}1.382 \\
(0.053) \\
\end{array}$ & $\begin{array}{c}0.263 \\
(0.031) \\
\end{array}$ & $\begin{array}{c}0.056 \\
(0.004) \\
\end{array}$ & 1.311 & 0.689 \\
\hline Italy & $\begin{array}{l}\text { mean } \\
\text { std. }\end{array}$ & $\begin{array}{c}0.083 \\
(0.276) \\
\end{array}$ & $\begin{array}{c}1.496 \\
(0.252) \\
\end{array}$ & $\begin{array}{c}0.486 \\
(0.032) \\
\end{array}$ & $\begin{array}{c}0.082 \\
(0.003) \\
\end{array}$ & 1.565 & $\begin{array}{c}0.590 \\
.\end{array}$ \\
\hline Luxemb & $\begin{array}{l}\text { mean } \\
\text { std. }\end{array}$ & $\begin{array}{c}0.184 \\
(0.388) \\
\end{array}$ & $\begin{array}{c}1.622 \\
(0.154) \\
\end{array}$ & $\begin{array}{c}0.518 \\
(0.041) \\
\end{array}$ & $\begin{array}{c}0.087 \\
(0.005) \\
\end{array}$ & 1.626 & 0.460 \\
\hline Mexico & $\begin{array}{l}\text { mean } \\
\text { std. }\end{array}$ & $\begin{array}{c}0.175 \\
(0.380) \\
\end{array}$ & $\begin{array}{c}3.068 \\
(0.576) \\
\end{array}$ & $\begin{array}{c}1.070 \\
(0.031) \\
\end{array}$ & $\begin{array}{c}0.117 \\
(0.002) \\
\end{array}$ & 3.548 & 0.734 \\
\hline Nether & $\begin{array}{l}\text { mean } \\
\text { std. }\end{array}$ & $\begin{array}{c}0.279 \\
(0.448) \\
\end{array}$ & $\begin{array}{c}1.374 \\
(0.141) \\
\end{array}$ & $\begin{array}{c}0.344 \\
(0.033) \\
\end{array}$ & $\begin{array}{c}0.057 \\
(0.005) \\
\end{array}$ & $\begin{array}{c}1.294 \\
.\end{array}$ & $\begin{array}{c}0.502 \\
.\end{array}$ \\
\hline Norway & $\begin{array}{l}\text { mean } \\
\text { std. }\end{array}$ & $\begin{array}{c}0.300 \\
(0.458)\end{array}$ & $\begin{array}{c}1.371 \\
(0.105)\end{array}$ & $\begin{array}{c}0.452 \\
(0.040)\end{array}$ & $\begin{array}{c}0.089 \\
(0.007)\end{array}$ & 1.572 & $\begin{array}{c}0.507 \\
.\end{array}$ \\
\hline Panama & $\begin{array}{l}\text { mean } \\
\text { std. }\end{array}$ & $\begin{array}{c}0.194 \\
(0.395) \\
\end{array}$ & $\begin{array}{c}3.241 \\
(0.913) \\
\end{array}$ & $\begin{array}{c}1.190 \\
(0.042) \\
\end{array}$ & $\begin{array}{c}0.146 \\
(0.003) \\
\end{array}$ & $\begin{array}{c}2.071 \\
. \\
\end{array}$ & $\begin{array}{c}0.647 \\
. \\
\end{array}$ \\
\hline Paraguay & $\begin{array}{l}\text { mean } \\
\text { std. }\end{array}$ & $\begin{array}{c}0.083 \\
(0.277) \\
\end{array}$ & $\begin{array}{c}3.567 \\
(1.945) \\
\end{array}$ & $\begin{array}{c}1.311 \\
(0.080) \\
\end{array}$ & $\begin{array}{c}0.165 \\
(0.006) \\
\end{array}$ & 3.040 & 0.682 \\
\hline Peru & $\begin{array}{l}\text { mean } \\
\text { std. }\end{array}$ & $\begin{array}{c}0.218 \\
(0.413) \\
\end{array}$ & $\begin{array}{c}2.661 \\
(0.698) \\
\end{array}$ & $\begin{array}{c}0.910 \\
(0.062) \\
\end{array}$ & $\begin{array}{c}0.133 \\
(0.006)\end{array}$ & $\begin{array}{c}2.462 \\
.\end{array}$ & $\begin{array}{c}0.686 \\
.\end{array}$ \\
\hline Poland & $\begin{array}{l}\text { mean } \\
\text { std. }\end{array}$ & $\begin{array}{c}0.101 \\
(0.302) \\
\end{array}$ & $\begin{array}{c}1.370 \\
(0.011) \\
\end{array}$ & $\begin{array}{c}0.339 \\
(0.028) \\
\end{array}$ & $\begin{array}{c}0.045 \\
(0.003) \\
\end{array}$ & 1.387 & 0.534 \\
\hline Slovakia & $\begin{array}{l}\text { mean } \\
\text { std. }\end{array}$ & $\begin{array}{c}0.151 \\
(0.358) \\
\end{array}$ & $\begin{array}{c}1.531 \\
(0.027) \\
\end{array}$ & $\begin{array}{c}0.427 \\
(0.015) \\
\end{array}$ & $\begin{array}{c}0.056 \\
(0.002) \\
\end{array}$ & $\begin{array}{c}1.491 \\
.\end{array}$ & 0.595 \\
\hline Spain & $\begin{array}{l}\text { mean } \\
\text { std. }\end{array}$ & $\begin{array}{c}0.213 \\
(0.409) \\
\end{array}$ & $\begin{array}{c}1.652 \\
(0.111) \\
\end{array}$ & $\begin{array}{c}0.543 \\
(0.019) \\
\end{array}$ & $\begin{array}{c}0.065 \\
(0.002) \\
\end{array}$ & 1.732 & 0.706 \\
\hline Sweden & $\begin{array}{l}\text { mean } \\
\text { std. }\end{array}$ & $\begin{array}{c}0.318 \\
(0.466) \\
\end{array}$ & $\begin{array}{c}1.421 \\
(0.141) \\
\end{array}$ & $\begin{array}{c}0.407 \\
(0.031) \\
\end{array}$ & $\begin{array}{c}0.057 \\
(0.004) \\
\end{array}$ & $\begin{array}{c}1.375 \\
. \\
\end{array}$ & $\begin{array}{c}0.444 \\
. \\
\end{array}$ \\
\hline Taiwan & $\begin{array}{l}\text { mean } \\
\text { std. }\end{array}$ & $\begin{array}{c}0.264 \\
(0.441) \\
\end{array}$ & $\begin{array}{c}1.620 \\
(0.050) \\
\end{array}$ & $\begin{array}{c}0.507 \\
(0.014) \\
\end{array}$ & $\begin{array}{c}0.079 \\
(0.002) \\
\end{array}$ & 1.610 & 0.670 \\
\hline Uruguay & $\begin{array}{l}\text { mean } \\
\text { std. }\end{array}$ & $\begin{array}{c}0.237 \\
(0.425) \\
\end{array}$ & $\begin{array}{c}2.283 \\
(0.039) \\
\end{array}$ & $\begin{array}{c}0.825 \\
(0.020) \\
\end{array}$ & $\begin{array}{c}0.110 \\
(0.002) \\
\end{array}$ & $\begin{array}{c}2.169 \\
.\end{array}$ & $\begin{array}{c}0.545 \\
.\end{array}$ \\
\hline$\overline{U S A}$ & $\begin{array}{l}\text { mean } \\
\text { std. }\end{array}$ & $\begin{array}{c}0.604 \\
(0.489) \\
\end{array}$ & $\begin{array}{c}1.724 \\
(0.204) \\
\end{array}$ & $\begin{array}{c}0.528 \\
(0.011) \\
\end{array}$ & $\begin{array}{c}0.123 \\
(0.002) \\
\end{array}$ & 1.753 & 0.611 \\
\hline Venezuela & $\begin{array}{l}\text { mean } \\
\text { std. }\end{array}$ & $\begin{array}{c}0.159 \\
(0.366) \\
\end{array}$ & $\begin{array}{c}1.990 \\
(0.467) \\
\end{array}$ & $\begin{array}{c}0.649 \\
(0.035) \\
\end{array}$ & $\begin{array}{c}0.071 \\
(0.003) \\
\end{array}$ & $\begin{array}{c}2.154 \\
. \\
\end{array}$ & $\begin{array}{c}0.625 \\
. \\
\end{array}$ \\
\hline Sample & $\begin{array}{l}\text { mean } \\
\text { std. }\end{array}$ & $\begin{array}{c}0.243 \\
(0.125)\end{array}$ & $\begin{array}{c}2.050 \\
(0.834)\end{array}$ & $\begin{array}{c}0.672 \\
(0.341)\end{array}$ & $\begin{array}{c}0.095 \\
(0.035)\end{array}$ & $\begin{array}{c}1.977 \\
(0.720)\end{array}$ & $\begin{array}{c}0.610 \\
(0.106)\end{array}$ \\
\hline
\end{tabular}


Table 2: Correlations

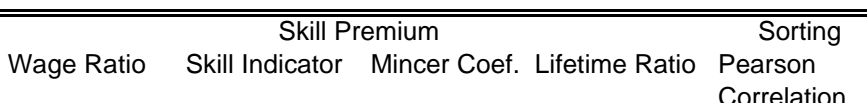

\begin{tabular}{l|ccccc}
\hline \multicolumn{1}{c|}{ Skill Premium } & & & & Correlation \\
Wage Ratio & 1.000 & & & \\
& & & & \\
Skill Indicator & 0.959 & 1.000 & & & \\
& $(0.000)$ & & & & \\
Mincer Coef. & 0.838 & 0.883 & 1.000 & & \\
& $(0.000)$ & $(0.000)$ & & & \\
Lifetime Ratio & 0.945 & 0.934 & 0.799 & 1.000 & \\
$\quad(0.000)$ & $(0.000)$ & $(0.000)$ & & \\
$\quad$ Sorting & & & & & \\
Pearson Correlation & 0.618 & 0.640 & 0.568 & 0.647 & 1.000 \\
& $(0.000)$ & $(0.000)$ & $(0.000)$ & $(0.000)$ & $(0.000)$ \\
\hline \hline
\end{tabular}

Significance levels are shown in paranthesis

Table 3: Regression of Marital Sorting on Skill Premium

\begin{tabular}{|c|c|c|c|c|c|c|c|c|}
\hline & \multicolumn{8}{|c|}{ Skill Premium Measure } \\
\hline & \multicolumn{2}{|c|}{ (a) Wage Ratio } & \multicolumn{2}{|c|}{ (b) Skill Indicator } & \multicolumn{2}{|c|}{ (c) Mincer Coef. } & \multicolumn{2}{|c|}{ (d) Lifetime Ratio } \\
\hline Explanatory Variable & 1 & 2 & 1 & 2 & 1 & 2 & 1 & 2 \\
\hline Constant & $\begin{array}{c}0.449 \\
(0.038)^{\star * *}\end{array}$ & $\begin{array}{c}0.487 \\
(0.042)^{* * *}\end{array}$ & $\begin{array}{c}0.476 \\
(0.035)^{\star * *}\end{array}$ & $\begin{array}{c}0.495 \\
(0.043)^{* * *}\end{array}$ & $\begin{array}{c}0.448 \\
(0.047)^{\star \star *}\end{array}$ & $\begin{array}{c}0.493 \\
(0.049)^{* * *}\end{array}$ & $\begin{array}{c}0.421 \\
(0.042)^{\star \star *}\end{array}$ & $\begin{array}{c}0.456 \\
(0.046)^{\star * *}\end{array}$ \\
\hline Skill Premium & $\begin{array}{l}0.079 \\
(0.014)^{\star * *}\end{array}$ & $\begin{array}{l}0.049 \\
(0.022)^{\star *}\end{array}$ & $\begin{array}{l}0.199 \\
(0.039)^{\star \star \star}\end{array}$ & $\begin{array}{c}0.147 \\
(0.075)^{*}\end{array}$ & $\begin{array}{l}1.708 \\
(0.391)^{\star \star *}\end{array}$ & $\begin{array}{c}0.889 \\
(0.462)^{*}\end{array}$ & $\begin{array}{l}0.095 \\
(0.016)^{\star * *}\end{array}$ & $\begin{array}{l}0.069 \\
(0.024)^{* *}\end{array}$ \\
\hline LA Dummy & & $\begin{array}{c}0.063 \\
(0.045)\end{array}$ & & $\begin{array}{c}0.042 \\
(0.052)\end{array}$ & & $\begin{array}{l}0.086 \\
(0.032)^{\star *}\end{array}$ & & $\begin{array}{c}0.048 \\
(0.041)\end{array}$ \\
\hline Number of Obs. & 34 & 34 & 34 & 34 & 34 & 34 & 34 & 34 \\
\hline Adjusted R-squared & 0.363 & 0.372 & 0.392 & 0.383 & 0.302 & 0.371 & 0.400 & 0.399 \\
\hline
\end{tabular}

Standard errors reflect Eicker-White correction for heteroscedasticity.

* Significant at $10 \%$.

** Significant at $5 \%$.

*** Significant at $1 \%$ 
Table 3a: Regression of Marital Sorting on Skill Premium, LIS Subsample

\begin{tabular}{|c|c|c|c|c|}
\hline & \multicolumn{4}{|c|}{ Skill Premium Measure } \\
\hline & $\begin{array}{c}\text { (a) Wage } \\
\text { Ratio }\end{array}$ & $\begin{array}{l}\text { (b) Skill } \\
\text { Indicator }\end{array}$ & $\begin{array}{l}\text { (c) Mincer } \\
\text { Coef. }\end{array}$ & $\begin{array}{l}\text { (d) Lifetime } \\
\text { Ratio }\end{array}$ \\
\hline \multicolumn{5}{|l|}{ Explanatory Variable } \\
\hline Constant & $\begin{array}{c}0.142 \\
(0.167)\end{array}$ & $\begin{array}{c}0.433 \\
(0.095)^{\star * *}\end{array}$ & $\begin{array}{c}0.468 \\
(0.065)^{* * *}\end{array}$ & $\begin{array}{c}0.277 \\
(0.150)^{*}\end{array}$ \\
\hline Skill Premium & $\begin{array}{c}0.275 \\
(0.104)^{\star *}\end{array}$ & $\begin{array}{c}0.287 \\
(0.194)\end{array}$ & $\begin{array}{c}1.215 \\
(0.650)^{*}\end{array}$ & $\begin{array}{c}0.186 \\
(0.092)^{*}\end{array}$ \\
\hline Number of Obs. & 21 & 21 & 21 & 21 \\
\hline Adjusted R-squared & 0.194 & 0.073 & 0.045 & 0.110 \\
\hline
\end{tabular}

Standard errors reflect Eicker-White correction for heteroscedasticity.

* Significant at $10 \%$.

** Significant at 5\%.

Table 3b: Regression of Marital Sorting on Skill Premium, LA Subsample

\begin{tabular}{|c|c|c|c|c|}
\hline & \multicolumn{4}{|c|}{ Skill Premium Measure } \\
\hline & $\begin{array}{l}\text { (a) Wage } \\
\text { Ratio }\end{array}$ & $\begin{array}{l}\text { (b) Skill } \\
\text { Indicator }\end{array}$ & $\begin{array}{l}\text { (c) Mincer } \\
\text { Coef. }\end{array}$ & $\begin{array}{l}\text { (d) Lifetime } \\
\text { Ratio }\end{array}$ \\
\hline \multicolumn{5}{|l|}{ Explanatory Variable } \\
\hline Constant & $\begin{array}{c}0.604 \\
(0.074)^{\star \star *}\end{array}$ & $\begin{array}{c}0.593 \\
(0.082)^{\star * *}\end{array}$ & $\begin{array}{c}0.626 \\
(0.082)^{\star \star \star}\end{array}$ & $\begin{array}{c}0.558 \\
(0.071)^{\star \star \star}\end{array}$ \\
\hline Skill Premium & $\begin{array}{c}0.030 \\
(0.022)\end{array}$ & $\begin{array}{c}0.094 \\
(0.069)\end{array}$ & $\begin{array}{c}0.508 \\
(0.574)\end{array}$ & $\begin{array}{l}0.049 \\
(0.022)^{\star *}\end{array}$ \\
\hline Number of Obs. & 13 & 13 & 13 & 13 \\
\hline Adjusted R-squared & 0.052 & 0.057 & 0.056 & 0.185 \\
\hline
\end{tabular}

Standard errors reflect Eicker-White correction for heteroscedasticity.

* Significant at $10 \%$.

** Significant at $5 \%$.

*** Significant at $1 \%$

Table 4: Regression of Marital Sorting on Skill Premium

Skill Premium Measure

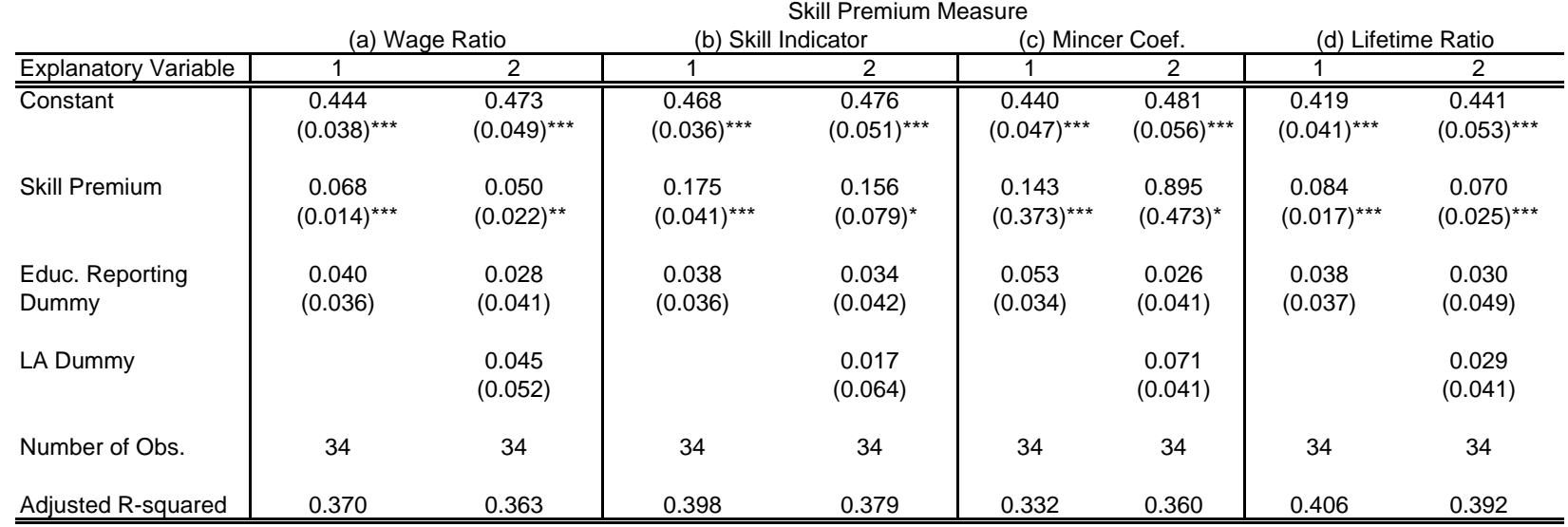

Standard errors reflect Eicker-White correction for heteroscedasticity.

* Significant at 10\%.

** Significant at $5 \%$.

*** Significant at $1 \%$ 
Table 5: Regression of Marital Sorting on Skill Premium

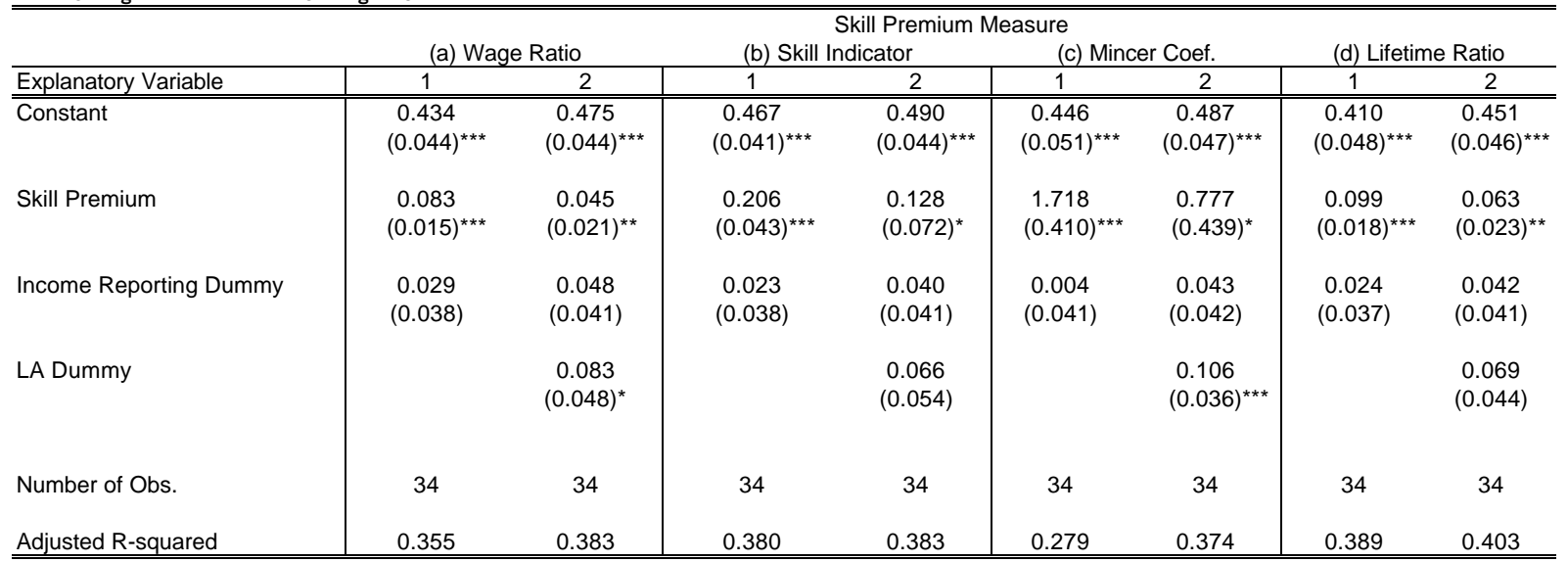

Standard errors reflect Eicker-White correction for heteroscedasticity.

* Significant at $10 \%$.

** Significant at $5 \%$

*** Significant at $1 \%$

Table 6: Regression of Marital Sorting on Skill Premium

\begin{tabular}{|c|c|c|c|c|c|c|c|c|}
\hline \multirow{3}{*}{ Explanatory Variable } & \multicolumn{8}{|c|}{ Skill Premium Measure } \\
\hline & \multicolumn{2}{|c|}{ (a) Wage Ratio } & \multicolumn{2}{|c|}{ (b) Skill Indicator } & \multicolumn{2}{|c|}{ (c) Mincer Coef. } & \multicolumn{2}{|c|}{ (d) Lifetime Ratio } \\
\hline & 1 & 2 & 1 & 2 & 1 & 2 & 1 & 2 \\
\hline Constant & $\begin{array}{l}0.471 \\
(0.046)^{\star \star *}\end{array}$ & $\begin{array}{c}0.502 \\
(0.048)^{\star \star \star}\end{array}$ & $\begin{array}{c}0.477 \\
(0.043)^{\star \star *}\end{array}$ & $\begin{array}{c}0.498 \\
(0.047)^{\star \star *}\end{array}$ & $\begin{array}{c}0.505 \\
(0.045)^{\star \star *}\end{array}$ & $\begin{array}{l}0.517 \\
(0.047)^{\star * *}\end{array}$ & $\begin{array}{c}0.435 \\
(0.049)^{\star * *}\end{array}$ & $\begin{array}{c}0.465 \\
(0.049)^{\star \star *}\end{array}$ \\
\hline Skill Premium & $\begin{array}{l}0.075 \\
(0.014)^{* * *}\end{array}$ & $\begin{array}{l}0.046 \\
(0.022)^{\star *}\end{array}$ & $\begin{array}{l}0.199 \\
(0.041)^{\star * *}\end{array}$ & $\begin{array}{l}0.145 \\
(0.072)^{*}\end{array}$ & $\begin{array}{l}1.534 \\
(0.377)^{\star \star \star}\end{array}$ & $\begin{array}{l}0.893 \\
(0.481)^{*}\end{array}$ & $\begin{array}{l}0.092 \\
(0.017)^{\star * *}\end{array}$ & $\begin{array}{c}0.067 \\
(0.023)^{\star \star \star}\end{array}$ \\
\hline Fraction of Skilled Population & $\begin{array}{l}-0.058 \\
(0.088)\end{array}$ & $\begin{array}{l}-0.042 \\
(0.097)\end{array}$ & $\begin{array}{c}-0.003 \\
(0.080)\end{array}$ & $\begin{array}{l}-0.008 \\
(0.084)\end{array}$ & $\begin{array}{l}-0.167 \\
(0.077)^{\star \star}\end{array}$ & $\begin{array}{l}-0.088 \\
(0.098)\end{array}$ & $\begin{array}{l}-0.034 \\
(0.081)\end{array}$ & $\begin{array}{l}-0.023 \\
(0.089)\end{array}$ \\
\hline LA Dummy & & $\begin{array}{c}0.061 \\
(0.047)\end{array}$ & & $\begin{array}{c}0.042 \\
(0.053)\end{array}$ & & $\begin{array}{l}0.076 \\
(0.038)^{*}\end{array}$ & & $\begin{array}{c}0.047 \\
(0.042)\end{array}$ \\
\hline Number of Obs. & 34 & 34 & 34 & 34 & 34 & 34 & 34 & 34 \\
\hline Adjusted R-squared & 0.346 & 0.353 & 0.372 & 0.362 & 0.317 & 0.359 & 0.382 & 0.380 \\
\hline
\end{tabular}

Standard errors reflect Eicker-White correction for heteroscedasticity.

* Significant at $10 \%$.

** Significant at $5 \%$.

*** Significant at $1 \%$ 
Table 7: Regression of Marital Sorting on Skill Premium

\begin{tabular}{|c|c|c|c|c|c|c|c|c|c|c|}
\hline Explanatory Variables & 1 & 2 & 3 & 4 & 5 & 6 & 7 & 8 & 9 & 10 \\
\hline Constant & $\begin{array}{c}0.384 \\
(0.045)^{\star \star \star}\end{array}$ & $\begin{array}{c}0.424 \\
(0.046)^{\star \star \star}\end{array}$ & $\begin{array}{c}0.530 \\
(0.085)^{\star \star \star}\end{array}$ & $\begin{array}{c}0.590 \\
(0.086)^{\star \star \star}\end{array}$ & $\begin{array}{c}0.621 \\
(0.054)^{\star \star \star}\end{array}$ & $\begin{array}{c}0.620 \\
(0.055)^{\star \star \star}\end{array}$ & $\begin{array}{c}0.833 \\
(0.111)^{\star \star \star}\end{array}$ & $\begin{array}{c}0.866 \\
(0.130)^{\star \star \star}\end{array}$ & $\begin{array}{c}0.888 \\
(0.151)^{\star \star \star}\end{array}$ & $\begin{array}{c}0.946 \\
(0.136)^{\star \star \star}\end{array}$ \\
\hline Skill Premium (Wage Ratio) & $\begin{array}{c}0.086 \\
(0.014)^{\star \star \star \star}\end{array}$ & $\begin{array}{c}0.058 \\
(0.019)^{\star \star \star \star}\end{array}$ & $\begin{array}{l}0.077 \\
(0.013)^{\star \star \star}\end{array}$ & $\begin{array}{c}0.042 \\
(0.021)^{\star}\end{array}$ & $\begin{array}{l}0.038 \\
(0.015)^{\star \star}\end{array}$ & $\begin{array}{c}0.039 \\
(0.020)^{\star}\end{array}$ & $\begin{array}{c}0.043 \\
(0.017)^{\star \star}\end{array}$ & $\begin{array}{l}0.052 \\
(0.021)^{\star \star}\end{array}$ & $\begin{array}{l}0.036 \\
(0.021)^{\star}\end{array}$ & $\begin{array}{l}0.050 \\
(0.019)^{\star *}\end{array}$ \\
\hline Ethnic Fractionalization & $\begin{array}{l}0.002 \\
(0.000)^{\star \star}\end{array}$ & $\begin{array}{c}0.002 \\
(0.000)^{\star \star}\end{array}$ & & & & & & & $\begin{array}{c}0.001 \\
(0.001)\end{array}$ & $\begin{array}{c}0.001 \\
(0.000)^{*}\end{array}$ \\
\hline Urbanization & & & $\begin{array}{l}-0.001 \\
(0.001)\end{array}$ & $\begin{array}{l}-0.001 \\
(0.001)\end{array}$ & & & & & $\begin{array}{l}-0.001 \\
(0.001)\end{array}$ & $\begin{array}{c}0.000 \\
(0.001)\end{array}$ \\
\hline$\%$ of Labor Force Female & & & & & $\begin{array}{l}-0.008 \\
(0.002)^{\star \star \star}\end{array}$ & $\begin{array}{l}-0.009 \\
(0.003)^{\star \star \star}\end{array}$ & & & $\begin{array}{l}-0.008 \\
(0.002)^{\star \star \star}\end{array}$ & $\begin{array}{l}-0.008 \\
(0.002)^{\star \star \star \star}\end{array}$ \\
\hline GDP per capita & & & & & & & $\begin{array}{l}-8.89 \mathrm{E}-06 \\
(2.56 \mathrm{E}-06)^{\star \star \star}\end{array}$ & $\begin{array}{c}-9.03 \mathrm{E}-06 \\
(2.87 \mathrm{E}-06)^{\star \star \star}\end{array}$ & $\begin{array}{c}-2.73 E-06 \\
(3.34 E-06)\end{array}$ & $\begin{array}{c}-9.86 \mathrm{E}-06 \\
(7.52 \mathrm{E}-06)\end{array}$ \\
\hline LA Dummy & & $\begin{array}{c}0.058 \\
(0.041)\end{array}$ & & $\begin{array}{c}0.071 \\
(0.045)\end{array}$ & & $\begin{array}{l}-0.027 \\
(0.050)\end{array}$ & & $\begin{array}{l}-0.005 \\
(0.042)\end{array}$ & & $\begin{array}{l}-0.107 \\
(0.074)\end{array}$ \\
\hline Number of Obs. & 30 & 30 & 34 & 34 & 34 & 34 & 32 & 32 & 28 & 28 \\
\hline Adjusted R-squared & 0.451 & 0.454 & 0.361 & 0.379 & 0.495 & 0.479 & 0.494 & 0.480 & 0.566 & 0.572 \\
\hline
\end{tabular}

Standard errors reflect Eicker-White correction for heteroscedasticity.

* Significant at $10 \%$.

** Significant at $5 \%$.

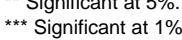

Table 8: Regression of Marital Sorting on Skill Premium, IV

\begin{tabular}{|c|c|c|c|c|c|c|c|c|}
\hline \multirow[b]{3}{*}{ Explanatory Variable } & \multicolumn{8}{|c|}{$\begin{array}{l}\text { Skill Premium Measure } \\
\end{array}$} \\
\hline & \multicolumn{2}{|c|}{ (a) Wage Ratio } & \multicolumn{2}{|c|}{ (b) Skill Indicator } & \multicolumn{2}{|c|}{ (c) Mincer Coef. } & \multicolumn{2}{|c|}{ (d) Lifetime Ratio } \\
\hline & 1 & 2 & 1 & 2 & 1 & 2 & 1 & 2 \\
\hline \multirow[b]{2}{*}{ Constant } & \multicolumn{8}{|c|}{ Two Stage Least Square } \\
\hline & $\begin{array}{c}0.260 \\
(0.084)^{\star \star \star \star}\end{array}$ & $\begin{array}{c}0.064 \\
(0.118)\end{array}$ & $\begin{array}{c}0.299 \\
(0.077)^{\star \star \star}\end{array}$ & $\begin{array}{c}0.104 \\
(0.109)\end{array}$ & $\begin{array}{c}0.254 \\
(0.085)^{\star \star \star \star}\end{array}$ & $\begin{array}{c}0.072 \\
(0.116)\end{array}$ & $\begin{array}{c}0.257 \\
(0.085)^{\star \star \star}\end{array}$ & $\begin{array}{c}0.131 \\
(0.105)\end{array}$ \\
\hline Skill Premium & $\begin{array}{c}0.151 \\
(0.028)^{\star \star \star}\end{array}$ & $\begin{array}{l}0.298 \\
(0.061)^{\star \star \star}\end{array}$ & $\begin{array}{l}0.376 \\
(0.071)^{\star \star \star}\end{array}$ & $\begin{array}{c}0.830 \\
(0.171)^{\star \star \star}\end{array}$ & $\begin{array}{l}3.773 \\
(0.720)^{\star \star \star}\end{array}$ & $\begin{array}{l}7.064 \\
(1.455)^{\star \star \star}\end{array}$ & $\begin{array}{l}0.161 \\
(0.031)^{\star \star \star}\end{array}$ & $\begin{array}{c}0.261 \\
(0.054)^{\star \star \star \star}\end{array}$ \\
\hline Fraction of Skilled Pop. & $\begin{array}{c}0.175 \\
(0.107)\end{array}$ & $\begin{array}{l}0.170 \\
(0.098)^{*}\end{array}$ & $\begin{array}{c}0.248 \\
(0.117)^{\star \star}\end{array}$ & $\begin{array}{c}0.330 \\
(0.119)^{\star \star}\end{array}$ & $\begin{array}{c}0.004 \\
(0.089)\end{array}$ & $\begin{array}{l}-0.150 \\
(0.085)^{\star}\end{array}$ & $\begin{array}{c}0.150 \\
(0.104)\end{array}$ & $\begin{array}{c}0.131 \\
(0.095)\end{array}$ \\
\hline LA Dummy & & $\begin{array}{l}-0.267 \\
(0.073)^{\star \star \star}\end{array}$ & & $\begin{array}{l}-0.333 \\
(0.086)^{\star \star \star}\end{array}$ & & $\begin{array}{l}-0.241 \\
(0.068)^{\star \star \star}\end{array}$ & & $\begin{array}{l}-0.171 \\
(0.055)^{\star \star \star}\end{array}$ \\
\hline \multirow[t]{2}{*}{ Adjusted R-squared } & 0.476 & 0.495 & 0.476 & 0.495 & 0.476 & 0.495 & 0.476 & 0.495 \\
\hline & \multicolumn{8}{|c|}{ First Stage for The Skill Premium } \\
\hline Constant & $\begin{array}{l}4.198 \\
(0.573)^{\star \star \star}\end{array}$ & $\begin{array}{l}2.522 \\
(0.454)^{\star \star \star}\end{array}$ & $\begin{array}{l}1.582 \\
(0.199)^{\star \star \star}\end{array}$ & $\begin{array}{l}0.857 \\
(0.141)^{\star \star \star \star}\end{array}$ & $\begin{array}{c}0.170 \\
(0.023)^{\star \star \star}\end{array}$ & $\begin{array}{c}0.105 \\
(0.020)^{\star \star \star}\end{array}$ & $\begin{array}{c}3.950 \\
(0.460)^{\star \star \star}\end{array}$ & $\begin{array}{l}2.619 \\
(0.368)^{\star \star \star \star}\end{array}$ \\
\hline Average Years of Schooling & $\begin{array}{l}-0.219 \\
(0.068)^{\star \star \star}\end{array}$ & $\begin{array}{c}-0.091 \\
(0.048)^{\star}\end{array}$ & $\begin{array}{l}-0.088 \\
(0.027)^{\star \star \star}\end{array}$ & $\begin{array}{l}-0.033 \\
(0.015)^{\star \star}\end{array}$ & $\begin{array}{l}-0.009 \\
(0.003)^{\star \star}\end{array}$ & $\begin{array}{l}-0.004 \\
(0.002)\end{array}$ & $\begin{array}{l}-0.206 \\
(0.057)^{\star \star \star}\end{array}$ & $\begin{array}{l}-0.104 \\
(0.039)^{\star \star}\end{array}$ \\
\hline Fraction of Skilled Pop. & $\begin{array}{l}-1.753 \\
(0.746)^{\star \star}\end{array}$ & $\begin{array}{l}-0.707 \\
(0.473)\end{array}$ & $\begin{array}{l}-0.898 \\
(0.335)^{\star \star}\end{array}$ & $\begin{array}{l}-0.446 \\
(0.236)^{*}\end{array}$ & $\begin{array}{l}-0.025 \\
(0.048)\end{array}$ & $\begin{array}{c}0.016 \\
(0.048)\end{array}$ & $\begin{array}{l}-1.485 \\
(0.625)^{\star \star}\end{array}$ & $\begin{array}{l}-0.655 \\
(0.408)\end{array}$ \\
\hline LA Dummy & & $\begin{array}{l}1.070 \\
(0.175)^{\star \star \star}\end{array}$ & & $\begin{array}{l}0.463 \\
(0.061)^{\star \star \star \star}\end{array}$ & & $\begin{array}{c}0.041 \\
(0.010)^{\star \star \star}\end{array}$ & & $\begin{array}{l}0.849 \\
(0.161)^{\star \star \star \star}\end{array}$ \\
\hline Number of Obs. & 33 & 33 & 33 & 33 & 33 & 33 & 33 & 33 \\
\hline Adjusted R-squared & 0.446 & 0.681 & 0.505 & 0.770 & 0.259 & 0.443 & 0.506 & 0.703 \\
\hline
\end{tabular}

Standard errors reflect Eicker-White correction for heteroscedasticity.

* Significant at $10 \%$.

** Significant at $5 \%$

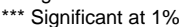


Table 9: Regression of GDP per capita on Marital Sorting

\begin{tabular}{|c|c|c|}
\hline Explanatory Variable & 1 & 2 \\
\hline Constant & $\begin{array}{l}33423.28 \\
(3999.08)^{\star * *}\end{array}$ & $\begin{array}{l}25431.90 \\
(3530.65)^{\star * *}\end{array}$ \\
\hline Sorting (Pearson Correlation) & $\begin{array}{l}-38566.00 \\
(6196.26)^{\star \star *}\end{array}$ & $\begin{array}{l}-21678.04 \\
(6427.10)^{\star \star *}\end{array}$ \\
\hline LA Dummy & & $\begin{array}{c}-6042.84 \\
(1499.69)^{\star \star \star}\end{array}$ \\
\hline Number of Obs. & 34 & 34 \\
\hline Adjusted R-squared & 0.458 & 0.612 \\
\hline
\end{tabular}


TABLE B1: Survey Information

\begin{tabular}{|c|c|c|c|c|c|}
\hline Country & Year & Name & Agency & $\begin{array}{l}\text { Number of } \\
\text { Households }\end{array}$ & Coverage \\
\hline Argentina & 1996 & Encuesta permanente de hogares & Instituto nacional de Estadistica y Censos & 3369 & Greater Buenos Aires \\
\hline Australia & 1994 & Australian Income and Housing Survey & Australian Bureau of Statistics & 7441 & National \\
\hline Belgium & 1992 & Panel Survey of the Centre for Social Policy & Centre for Social Policy & 3821 & National \\
\hline Bolivia & 1997 & Encuesta Nacional de Empleo & Instituto nacional de Estadistica y Censos & 8461 & National \\
\hline Brasil & 1996 & Pequiso Nacional por Amostra de Domicilios & $\begin{array}{c}\text { Fundaçao Instituto Brasileiro de Geografia e } \\
\text { Estatistica }\end{array}$ & 84947 & National \\
\hline Britain & 1997 & British Household Panel Study, Wave G & Institute for Social and Economic Research & 4384 & National \\
\hline Canada & 1994 & Survey of Consumer Finances & Statistics Canada & 39039 & National \\
\hline Chile & 1996 & Encuesta Nacional de Empleo & Instituto Nacional de Estadistica & 30953 & National \\
\hline Colombia & 1997 & Encuesta Nacional de Hogares & $\begin{array}{c}\text { Departamento Administrativo Nacional de } \\
\text { Estadistica }\end{array}$ & 31264 & National \\
\hline Costa Rica & 1996 & $\begin{array}{c}\text { Encuesta Permanente de hogares de Propositos } \\
\text { Multiples }\end{array}$ & Direccion General de Estadistica y Censos & 9471 & National \\
\hline Czech & 1992 & Microcensus & Czech Statistical Office & 16234 & National \\
\hline Denmark & 1992 & Income Tax Survey & National Institute of Social Research & 12895 & National \\
\hline Ecuador & 1996 & $\begin{array}{c}\text { Encuesta Periodica de Empleo y Desempleo en el Area } \\
\text { Urbana }\end{array}$ & Instituto nacional de Estadistica y Censos & 8153 & Urban \\
\hline Finland & 1995 & Income Distribution Survey & Statistics Finland & 9262 & National \\
\hline France & 1994 & Enquête Budget des familles & $\begin{array}{c}\text { INSEE } \\
\text { Division Conditions de vie des Ménages }\end{array}$ & 11294 & National \\
\hline Germany & 1994 & German Social Economic Panel Study & DIW Berlin & 6045 & National \\
\hline Hungary & 1994 & Hungarian Household Panel & Endre Sik / Istvan Toth & 1992 & National \\
\hline Israel & 1992 & Family Expenditure Survey & Israeli Central Bureau of Statistics & 5212 & National \\
\hline Italy & 1995 & Indagine Campionaria sui Bilanci Delle Famiglie & Ufficio Informazioni Statistiche & 8135 & National \\
\hline Luxemb & 1994 & Liewen zu Letzebuerg & $\begin{array}{l}\text { Centre d'Etudes de Populations, de Paurreté et } \\
\text { de Politiques Socio-Economiques }\end{array}$ & 1813 & National \\
\hline Mexico & 1996 & Encuesta Nacional de Increso Gasto de los Hogares & $\begin{array}{l}\text { Instituto Nacional de Estadistica, Geografia e } \\
\text { Informatica }\end{array}$ & 14042 & National \\
\hline Nether & 1994 & Socio-Economic Panel & Centraal Bureau voor de Statistiek & 5187 & National \\
\hline Norway & 1995 & Income and Property Distribution Survey & Statistics Norway & 10127 & National \\
\hline Panama & 1997 & Encuesta de Hogares & Direccion de Estadistica y Censo & 9897 & National \\
\hline Paraguay & 1998 & Encuesta Integrada de Hogares & $\begin{array}{c}\text { Direccion General de Estadistica, Encuestas y } \\
\text { Censos }\end{array}$ & 4353 & National \\
\hline Peru & 1997 & Encuesta de Hogares & Instituto Nacional de Estadistica e Informatica & 3843 & National \\
\hline Poland & 1992 & Household Budget Survey & Central Statistical Office & 6602 & National \\
\hline Slovakia & 1992 & Slovak Microcensus & $\begin{array}{l}\text { Statistical Office of the Slovak Republic } \\
\text { Division of SocialStatistics and Demography }\end{array}$ & 17714 & National \\
\hline Spain & 1990 & Expenditure and Income Survey & Instituto Nacional de Estadistica & 11294 & National \\
\hline Sweden & 1995 & Inkomstfördelningsundersokningen & $\begin{array}{c}\text { Statistics Sweden } \\
\text { Program for Income and Wealth }\end{array}$ & 16260 & National \\
\hline Taiwan & 1995 & Survey of Personal Income Distribution & Academia Sinica & 14706 & National \\
\hline Uruguay & 1996 & Encuesta Continua de Hogares & instituto nacional de Estadistica & 19322 & Urban \\
\hline USA & 1994 & March Current Population Survey & Bureau of Labor Statistics & 66014 & National \\
\hline Venezuela & 1996 & Encuesta de Hogares por Mustreo & Oficina Central de Estadistica e Informatica & 16323 & National \\
\hline
\end{tabular}




\begin{tabular}{|c|c|c|}
\hline Name & $\begin{array}{l}\text { Years of Schooling Beyond Which } \\
\text { A Person Qualifies as Skilled }\end{array}$ & $\begin{array}{l}\text { The LIS Education Level Beyond Which } \\
\text { A Person Qualifies as Skilled }\end{array}$ \\
\hline Australia & 12 & "Basic/Skilled Vocational Qualification \\
\hline Argentina & 12 & $N / A$ \\
\hline Belgium & 12 & $\begin{array}{l}\text { 2nd Level Upper Professional/Technical/ } \\
\text { General; Other 2nd Level Upper }\end{array}$ \\
\hline Bolivia & 12 & $\mathrm{~N} / \mathrm{A}$ \\
\hline Brazil & 11 & N/A \\
\hline Britain & 13 & A Level \\
\hline Canada & 12 & Grade 11-13; High School Grad. \\
\hline Chile & 11 & $\mathrm{~N} / \mathrm{A}$ \\
\hline Columbia & 11 & $\mathrm{~N} / \mathrm{A}$ \\
\hline Costa Rica & 11 & $N / A$ \\
\hline Czech & 12 & Secondary General/Professional \\
\hline Denmark & 10 & Level 2,2nd Stage \\
\hline Ecuador & 12 & $N / A$ \\
\hline Finland* & 12 & $N / A$ \\
\hline France & 12 & Second Stage of Secondary \\
\hline Germany & 10 & Secondary \\
\hline Hungary & 12 & Secondary \\
\hline |srael* & 12 & $N / A$ \\
\hline Italy & 12 & High School \\
\hline Luxembourg & 12 & Higher Secondary Education \\
\hline Mexico & 12 & $\mathrm{~N} / \mathrm{A}$ \\
\hline Nether & 12 & Secondary Higher \\
\hline Norway* & 12 & N/A \\
\hline Panama & 12 & $\mathrm{~N} / \mathrm{A}$ \\
\hline Paraguay & 12 & $\mathrm{~N} / \mathrm{A}$ \\
\hline Peru & 11 & $N / A$ \\
\hline Poland & 12 & Complete Secondary \\
\hline Slovakia & 12 & $\begin{array}{l}\text { Secondary/Secondary Special/Skilled } \\
\text { with Leaving Exam }\end{array}$ \\
\hline Spain & 12 & Secondary Education/Basic Tech. Edu. \\
\hline Sweden & 12 & Secondary School \\
\hline Taiwan & 10,12 & Senior High/Vocational Graduate \\
\hline Uruguay & 11 & $\mathrm{~N} / \mathrm{A}$ \\
\hline USA & 12 & High School Diploma \\
\hline Venezuela & 11 & $\mathrm{~N} / \mathrm{A}$ \\
\hline
\end{tabular}

* Finland, Israel and Norway report years of education 